Review Article

\title{
Melatonin to Rescue the Aged Heart: Antiarrhythmic and Antioxidant Benefits
}

\author{
Margarita Segovia-Roldan $\left(\mathbb{D},{ }^{1}\right.$ Emiliano Raúl Diez $\mathbb{D}^{2},{ }^{2}$ and Esther Pueyo $\mathbb{D}^{1}$ \\ ${ }^{1}$ Biomedical Signal Interpretation and Computational Simulation (BSICoS), I3A, Universidad de Zaragoza, \\ IIS Aragón and CIBER-BBN, Spain \\ ${ }^{2}$ CONICET, IMBECU, National University of Cuyo, Argentina
}

Correspondence should be addressed to Margarita Segovia-Roldan; margasr@unizar.es

Received 21 September 2020; Revised 16 January 2021; Accepted 23 January 2021; Published 15 March 2021

Academic Editor: Lillian Barros

Copyright $\odot 2021$ Margarita Segovia-Roldan et al. This is an open access article distributed under the Creative Commons Attribution License, which permits unrestricted use, distribution, and reproduction in any medium, provided the original work is properly cited.

Aging comes with gradual loss of functions that increase the vulnerability to disease, senescence, and death. The mechanisms underlying these processes are linked to a prolonged imbalance between damage and repair. Damaging mechanisms include oxidative stress, mitochondrial dysfunction, chronodisruption, inflammation, and telomere attrition, as well as genetic and epigenetic alterations. Several endogenous tissue repairing mechanisms also decrease. These alterations associated with aging affect the entire organism. The most devastating manifestations involve the cardiovascular system and may lead to lethal cardiac arrhythmias. Together with structural remodeling, electrophysiological and intercellular communication alterations during aging predispose to arrhythmic events. Despite the knowledge on repairing mechanisms in the cardiovascular system, effective antiaging strategies able to reduce the risk of arrhythmias are still missing. Melatonin is a promising therapeutic candidate due to its pleiotropic actions. This indoleamine regulates chronobiology and endocrine physiology. Of relevance, melatonin is an antiaging, antioxidant, antiapoptotic, antiarrhythmic, immunomodulatory, and antiproliferative molecule. This review focuses on the protective effects of melatonin on age-induced cardiac functional and structural alterations, potentially becoming a new fountain of youth for the heart.

\section{Introduction}

Cardiovascular diseases are the first cause of death globally $[1,2]$, with predominance in older populations. As many different mechanisms are involved in the relationship between cardiovascular disease and aging, a wide range of study models exploring different pathways have been developed to understand these processes [3]. An important proportion of deaths in patients suffering from cardiovascular diseases is associated with abnormalities in the rhythm of the heart, so-called cardiac arrhythmias. Not only in diseased patients but also in healthy populations, age is a major risk factor for arrhythmia development, causing substantial increases in the levels of morbidity and mortality $[4,5]$. Due to the extensive structural and functional remodeling of cardiac tissue in the elderly, arrhythmias can relatively frequently occur in individuals who never developed any cardiac condition before. Thus, there is an intensive effort to understand the mechanisms underlying age-induced arrhythmias, from the molecular to the whole-organ level, as well as a great interest in creating new strategies for their prevention that might also ameliorate cardiac function in the elderly.

Despite differences between individuals and species due to molecular mechanisms involving genetic and environmental variability, damage caused by oxidative stress is considered one of the main elements underlying the aging process $[6,7]$. Mitochondria have been shown as one of the most important regulators of aging [8]. Reactive oxidative species (ROS), among other oxidative molecules, have been associated with damaged and aged myocardium, playing an important role in cardiac physiology and pathophysiology, as in the case of atrial fibrillation (AF), the most commonly diagnosed cardiac arrhythmia with particularly high prevalence in the elderly [9].

Different drugs have been studied and used in pharmacotherapy to improve the fight against aging and cardiac arrhythmias [10-12]. Although these antiarrhythmic drugs 
must be used with caution in patients due to their potential adverse effects, positive results of some of them have been reported [13-15], including those of the molecule melatonin. Thanks to its pleiotropic action, melatonin is still considered one of the potentially good candidates for arrhythmia treatment and prevention $[16,17]$. Moreover, its antioxidant role should be considered as an important factor to understand its benefits in relation to aging [18-20].

In this review article, we present an overview of arrhythmias and their molecular mechanisms in aged hearts. Considering the pleiotropic effects of melatonin, we focus our interest on the action of this molecule in cardiac tissue. We highlight its potential as a drug against oxidative stress and for antiarrhythmic treatment in aged hearts, which could make melatonin a prospective candidate to become the fountain of youth for the heart.

\section{Aging: Body and Heart Rhythms}

2.1. Aging of the Heart. Aging is a complex process. As many human functions decline with age, the incidence and prevalence of diseases increase. Nevertheless, the apparent cycle of life postpones its ending due to human interventions. Improvements in access to shelter, water, and food have doubled life expectancy at birth in the past century. Despite disparities in social support or medical care underlying uneven life expectancy across countries, the proportion of older individuals keeps on increasing globally. This aging of the population comes associated with growing costs related to health care to the elderly all over the world [21].

The relationship between aging and age-related disease remains controversial [21-23]. Some postulate that such a distinction between pathological and nonpathological aging does not invalidate the fundamental underlying molecular mechanisms, which would be potentially shared in the two cases. On the other hand, others support a clear difference between aging and diseases, claiming that aging is not a disease itself but leads to higher vulnerability, implying that different molecular pathways would be involved in each case. For the purpose of this review, we accept that the basic mechanism of aging is the prolonged imbalance between damage and repair [24-26].

Overall, there are three great classes of mechanisms underlying the aging of the organism: (1) inadequate repair of damage, (2) cell number deregulation, and (3) damage caused by oxidative stress $[27,28]$. The factors underlying the damage-repair imbalance vary between species and between different individuals of the same species due to the effect of genetic processes and environmental variability.

Specifically in the cardiovascular system, a major problem in aged hearts is the generation of cardiac arrhythmias [29]. Although arrhythmias are most frequently related to heart diseases, they can also occur in nondiseased hearts, with the probability of occurrence exponentially increasing with age. Arrhythmias originating both in the atria and in the ventricles, such as AF, atrial flutter, premature ventricular contractions, ventricular tachycardias, or ventricular fibrillation [30], have an increased prevalence in elderly individuals. Changes in cardiac structure and function that accompany aging and possibly predispose the aged hearts to increased arrhythmic risk have been reported mainly in animal models due to the difficulties in assessing the effects of aging independently of disease in human hearts.

\subsection{Structural, Electrical, and Autonomic Changes in Aged Hearts}

2.2.1. Structural and Autonomic Changes. The heart undergoes age-induced structural changes. Different studies have documented atrial remodeling associated with larger atrial size and volume [31]. In the ventricle, structural remodeling has been associated with left ventricular hypertrophy related to increased wall thickness [32]. Also, there is a loss of cardiomyocytes in the heart by necrotic and apoptotic cell death with age [33]. Cellular mechanisms of senescence are yet to be fully understood in aging. There is evidence about the link between $\mathrm{AF}$ and the presence of senescence markers, one of them being p16 (p16 ${ }^{\mathrm{INK} 4 \mathrm{a}}$, cyclin-dependent kinase inhibitor 2A), which is involved in inflammation. Importantly, aging is characterized by notably increased fibrosis due to a rise in the number of cardiac fibroblasts $[34,35]$, which are the cells primarily responsible for the production of extracellular matrix components like collagen [36] and proteoglycans [37]. These changes are accompanied by alterations in the cell-to-cell coupling between neighbouring myocytes, which are mediated by changes in gap junction distribution and connexin expression [38].

Aging is additionally associated with changes in the autonomic nervous system (ANS), which regulates the activity of internal body organs like the heart, as well as in the cardiac response to autonomic stimuli [39, 40]. Regarding the sympathetic branch of the ANS, reduced responsiveness to sympathetic nerve stimulation of both aged atria and aged ventricles has been evidenced, although some studies have postulated that this occurs through different mechanisms. Whereas in the aged atria the involved mechanism may be related to decreased $\beta$-adrenergic responsiveness, in the aged ventricles it may be related to nerve degeneration $[41,42]$. Other studies have described that age alters cardiac adrenergic responsiveness, being the age-induced changes related to a reduction in the density of $\beta$-adrenoceptors and reduced cAMP in association with abnormalities in $G$ protein and kinase activity. Although these changes vary between tissues and between species [43], the ability of the heart to properly respond to autonomic stimuli has been generally documented to decrease with aging [44]. Reduced $\beta$-adrenoceptor responses and receptor densities have been identified in the aging myocardium [43, $45,46]$, exacerbated by decreased cAMP production. It is not fully clear how impaired cAMP-dependent regulation of the slow delayed rectifier potassium current (IKs) [47] and L-type calcium current (ICa-L) [48] translates into alterations of repolarization reserve in the elderly. On the other hand, less research has been dedicated to the investigation of aging effects on the cardiac response to parasympathetic stimuli $[49,50]$. Nevertheless, available studies suggest a reduction in parasympathetic regulation with age accompanied by blunted responsiveness of the heart to parasympathetic withdrawal [51]. The density and function of atrial muscarinic type 2 receptors are thought to decline with age [42]. Furthermore, some 
studies have specifically reported on how age alters the response of cardiac tissue to the interaction between sympathetic and parasympathetic stimuli, showing that the action of $\beta$-adrenergic stimulation to antagonize cholinergic effects declines in old atria, which could increase arrhythmia susceptibility [52].

The aged-induced structural remodeling and the impaired response to autonomic stimulation in aged hearts, together with the electrical remodeling described in Section 2.2.2, all contribute to reduced cardiac adaptive responses and increased risk for arrhythmias.

2.2.2. Electrophysiological Changes. Cardiac contraction is triggered by a bioelectrical signal, known as action potential (AP). The AP is the result of the electrical potential difference between the intra- and extracellular spaces and involves the opening and closing of complex transmembrane proteins known as ion channels, among other molecules. Both AP generation and propagation are key to ensure proper heart electrical function leading to optimal cardiac output $[53,54]$.

Aging is associated with remarkable electrical alterations leading to remodeling of both atrial and ventricular tissues $[55,56]$. In atrial myocardium, contradictory results on the effects of age on ionic currents have been described, with some studies indicating relevant changes in sodium currents and other studies showing no significant alterations in these currents with age $[57,58]$. Increased potassium and decreased calcium currents with age have been observed in atrial myocytes from older animals too. In the ventricular myocardium, decreased potassium currents as well as delayed inactivation and/or increased magnitude of calcium currents, accompanied by adjustments in calcium cycling, have been shown to contribute to prolonged AP with age [59, 60].

In addition to the remodeling leading to delayed and impaired cardiac impulse conduction due to a decrease in Connexin 43 (Cx43) expression with aging $[5,61,62]$, there are also electrophysiological alterations in the sinoatrial node involving depression of its activity, which could enhance initiation of the electrical impulse in other cells of the heart [63]. Animal studies suggest that decreased expression of potassium/sodium hyperpolarization-activated cyclic nucleotide-gated channel 2 , ICa-L current, T-type calcium current, and voltage-gated potassium $(\mathrm{Kv})$ channels (Kv1.5 channels) can also play a role [64-66].

Thus, age-associated ion channel remodeling in different cardiac regions involves alterations in several families of ion channels, with an impact on the AP [67, 68]. Those channels could be potential targets to help to maintain cardiac function in aged hearts [56].

2.3. Mechanisms Underlying Arrhythmias in Aged Hearts. Although evidence suggests that cardiac aging is associated with enhanced predisposition to arrhythmia development, improved knowledge of the mechanisms underlying the enhanced incidence of arrhythmias with aging is still needed. New pharmacological approaches that selectively target the molecular pathways involved in age-induced alterations increasing arrhythmic risk might help prevent cardiovascular diseases and retard the age-related decline in physiological processes.

Age-induced changes in major ionic currents leading to AP disturbances, together with other elements of structural, electrical, and autonomic remodeling in the heart, can increase arrhythmic risk $[69,70]$. In particular, an increase in the activity of the sodium-calcium exchanger (NCX) may induce calcium overload, which can trigger arrhythmias [71]. Increased expression of NCX and delayed inactivation of ICa-L, together with reduced expression of SERCA and other proteins related to calcium handling, all contribute to impaired calcium homeostasis and provide mechanisms for increased triggered activity in the aged myocardium [7276]. In addition, fibrosis accumulation and changes in gap junction distribution and connexin expression with aging lead to slower conduction in cardiac tissue, which increases arrhythmia predisposition [77-82].

Dysfunction or senescence of cardiomyocytes has been observed in aged hearts, with senescent cardiomyocytes exhibiting DNA damage response, endoplasmic reticulum stress, mitochondria dysfunction, contractile dysfunction, hypertrophic growth, and senescence-associated secretory phenotype [83]. Cellular senescence contributes to the loss of function and regenerative capacity of cardiac tissue and, although the environment of an individual determines the degree to which it can be a major causal factor for the organism's functional decline with aging, these changes and damage in the genome can induce inflammation and promote the adverse remodeling described above $[84,85]$.

Oxidative stress is one of the main damaging processes underlying aging. Indeed, increased production of ROS has been shown to underlie some of the already described elements of age-induced cardiac remodeling (Figure 1). The signaling pathway driven by ROS regulates cardiac development and maturation as well as calcium handling, excitationcontraction coupling, and vascular tone [86, 87]. Excessive ROS production can increase the threshold to trigger cardioprotection and, in relation to the described structural, autonomic, and electrical remodeling, could help explain the increased incidence of damage and the consequent increase in arrhythmia predisposition with aging [5], as further described in Section 3.

\section{Oxidative Mechanism of Arrhythmias and Antioxidant Antiarrhythmic Therapies}

The exposure to different types of damage over time is highly individual specific, partly explaining differences in the aging rate between individuals [88, 89]. Of the many factors contributing to aging of the body, and in particular of the heart, including genetics, epigenetics, diet, smoking, physical activity, and even chance [90-92], here, we will focus on the relationship between oxidative stress and age-induced arrhythmias and we will revise antioxidant therapies that could provide antiarrhythmic benefits.

3.1. Oxidative Stress in the Aging Heart and Relation to Arrhythmic Risk. Although the mechanisms responsible for senescence and remodeling in cardiomyocytes and aged hearts are not fully understood, mitochondria have emerged 


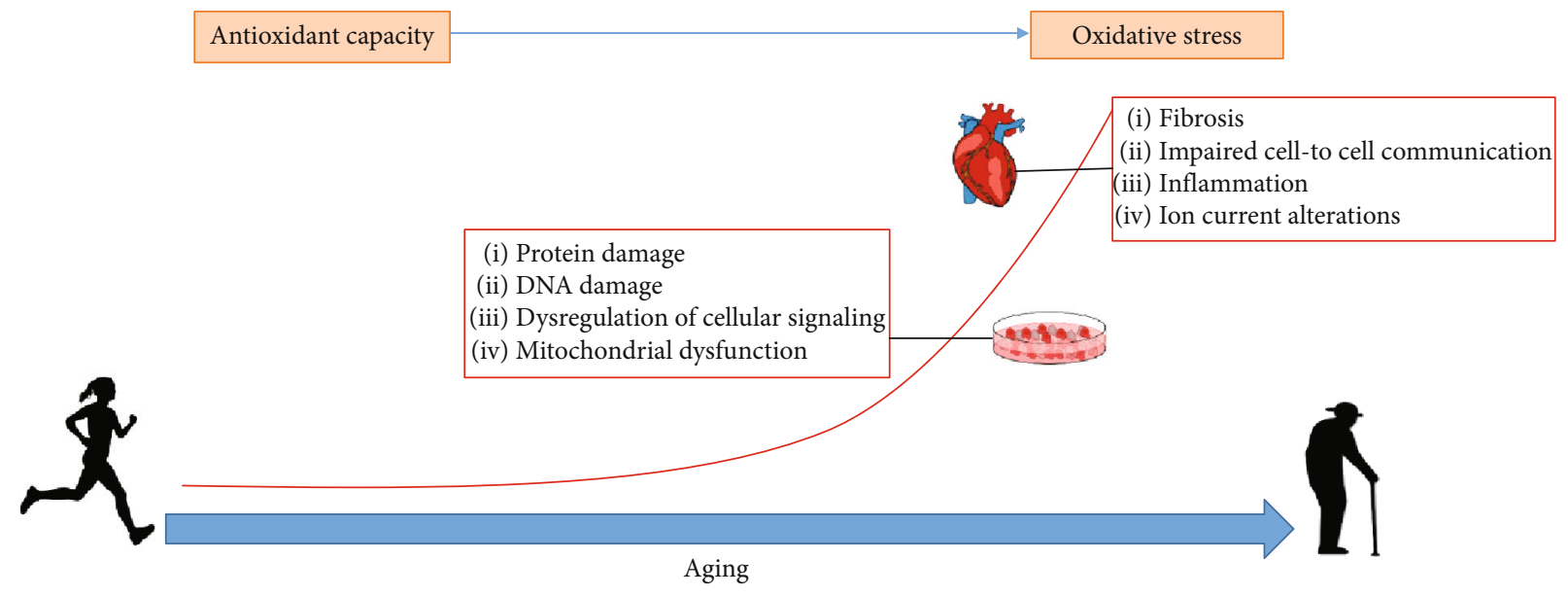

FIGURE 1: Schematic representation of different mechanisms, including increased production of reactive oxygen species, involved in age-induced remodeling of the heart, from cell to organ level.

as central regulators of the aging process $[8,86]$. In the aged myocardium, mitochondrial function is impaired at various levels including ROS formation, dynamics, and metabolism. Together with ROS, which is considered to be one of the primary determinants of aging [93-95], the superoxide anion, the hydroxyl radical, and hydrogen peroxide are in fact crucial molecules with important roles in cardiac physiology and pathophysiology through various signaling pathways [96].

Oxidative stress can work as a mediator of AF, with elevated levels of ROS having been linked to it [97, 98], both oxidative stress and AF being common in aged hearts. Also, prooxidant genes are overexpressed and many antioxidant genes are downregulated in AF. In addition, derivatives of reactive oxidative metabolites and ratios of oxidized to reduced glutathione and cysteine show high levels in blood from patients suffering AF [99]. ROS facilitates ventricular arrhythmia too, especially in aged and hypertensive rat hearts, with underlying mechanisms involving the generation of early afterdepolarizations [100].

Among the various possible ways for ROS to facilitate arrhythmia development, alterations in ionic currents have been revealed as an important factor [7, 101-103]. Ionic alterations due to elevated ROS have been observed in the sodiumpotassium ATPase $\left(\mathrm{Na} / \mathrm{K}\right.$-ATPase) pump, NCX, and $\mathrm{K}^{+}$and $\mathrm{Na}^{+}$channels $[104,105]$. In addition, the molecular mechanism of arrhythmias induced by ROS could be linked to hydrogen peroxide $\left(\mathrm{H}_{2} \mathrm{O}_{2}\right)$, a major contributor to oxidative stress, producing complex cardiac effects that may involve altered calcium homeostasis [106]. Moreover, there is evidence about how ROS may act on the ICa-L current producing a leak of $\mathrm{Ca}^{2+}$ from the sarcoplasmic reticulum (SR). Besides, ROS decreases peak sodium current and SERCA-mediated SR $\mathrm{Ca}^{2+}$ uptake. ROS participates in the inhibition of KATP channels [107] and decrease of the transient outward potassium current (Ito) [108], among others [109]. All these mechanisms are related to an increase in intracellular $\mathrm{Ca}^{2+}$ levels, AP prolongation, reduction in conduction velocity, and facilitation of triggered activity and reentry. Also, dysregulation of L-type calcium channels and an increase in late $\mathrm{Na}^{+}$current may result in arrhythmia [110-112]. The decrease in total $\mathrm{Na}^{+}$ current induced by elevated ROS may cause a reduction in conduction velocity and provide a substrate for reentry [113].

On top of oxidative stress causing alterations in ion channels, its potential contribution to cardiac arrhythmias by impairing intercellular communication has been additionally described, both in relation to aging and to various pathological states. This effect may result in changes in conduction properties. Specifically, elevated ROS levels decrease the expression and distribution of $\mathrm{Cx} 43$, the main component of gap junction channels in the ventricles and one of the most important connexins in the atria $[7,114,115]$. This impairs conduction through gap junctions and may facilitate cardiac arrhythmias $[116,117]$. Also, the effect of ROS radicals on cardiac structure by promoting high levels of fibrosis may impede the normal propagation of the AP across the heart. This effect is due to proliferation of cardiac fibroblasts by the high level of transforming growth factor beta 1 (TGF- $\beta 1$ ) production induced by increased ROS [118].

On the basis of the described mechanisms underpinning oxidative stress as a key contributor to arrhythmias, further studies delving into these different routes could help to identify molecules that can serve as therapeutic targets for oxidative stress in the aged heart with antiarrhythmic benefits.

3.2. Markers of Oxidative Stress: Role on Antiarrhythmic Therapies. Increased serum markers of oxidative stress might be an important guide in selecting the individuals who will most likely respond to antioxidant therapy and could benefit from its possible antiarrhythmic effects [99, 119]. Studies exploring novel molecular mechanisms for ROS-induced arrhythmia have led to the discovery of new potential antiarrhythmic targets.

Among the mentioned potential mechanisms to be considered as targets against arrhythmias via oxidative stress therapies, one of them is the abnormal splicing of cardiac sodium channel mRNA in heart failure. This is a possible mechanism underlying decreased sodium current in ranges associated with sudden cardiac death, suggesting that interruption of this processing could potentially reduce the 
arrhythmic risk $[113,120]$. Moreover, $\mathrm{Ca}^{2+} /$ calmodulindependent kinase II (CaMKII) can be activated by ROS and its activation likely mediates several of the reported ROSinduced arrhythmogenic effects [121-123]. Several studies have recently described the link between the use of CaMKII inhibitors and the improvement in catecholaminergic polymorphic ventricular tachycardia, helping to inhibit arrhythmic phenotypes [124]. As an additional mechanism that could represent a potential source of new antiarrhythmic targets, it is worth mentioning the impact of oxidative stress on the increased activity of ryanodine receptors (RyRs). Protein kinase A hyperphosphorylates cardiac RyRs, which results in a dysregulation of SR $\mathrm{Ca}^{2+}$, provoking a leak of calcium in failing hearts that can trigger fatal ventricular arrhythmias [10, 125-132].

However, the role of ROS scavengers is hampered by the ability of ROS radicals to react with other molecules. A general scavenger can usually neutralize one or a few forms of ROS, but other forms of ROS remain to exert their proarrhythmic effects. Clinical trials using general antioxidants have not shown the expected therapeutic outcome. A more effective antioxidant therapeutic approach targeting the sources of ROS could be more beneficial. Among cardiac sources of ROS, mitochondria and NADPH oxidase seem to be promising therapeutic targets for the management of $\mathrm{AF}$, a common arrhythmia in old age $[133,134]$. Because mitochondria play a central role in ROS-induced ROS release, mitochondriatargeted antioxidant therapy may prove to be the most effective antioxidant therapy for the management of chronic AF [86, 135-137].

The free radical theory of aging attributes aging processes to the accumulation of damage inflicted by free radical species. Among the different species involved in aging, we should mention some antioxidants such as superoxide dismutase, catalase, and metallothionein [138]. In Section 4, we will focus our attention on the role of melatonin as a potential antioxidant molecule against aging.

\section{Melatonin as a Potential Antiarrhythmic Treatment in Aging}

4.1. Melatonin and Cardiac Activity. Even if further studies in humans are needed, melatonin appears as a key molecule in heart aging. Melatonin is an amphipathic and pleiotropic molecule, being able to act on several targets at different levels and cell locations $[139,140]$. Melatonin was first discovered in the 1950s by Lerner et al. [141], and it is considered the molecule of the night, due to its increased levels during nighttime in the majority of animal species. Melatonin is mainly secreted by the pineal gland [142], and its production is considered to follow a rhythmical pattern, making it a molecule involved in biological seasonal and yearly rhythms of the organisms [143].

Melatonin has a double role in the sleep-wake cycle. This molecule is able to entrain and shift the circadian rhythm (chronobiotic function) and, in addition, plays its action on the sleeping process, helping through a "hypnotic" function by increasing the homeostatic drive to sleep [144]. At the level of the pineal gland, production and release of melatonin follow a clear circadian pattern, having its peak level of synthesis during nighttime [145]. Melatonin has been reported to have a cardioprotective role in various animal species [146]. In fact, increases in melatonin during nighttime are linked to a good cardiovascular function in different organisms. Reduced levels of melatonin are related to disease, aging, and chronodisruption.

Melatonin has an apparent antioxidant function, slows down aging, and expands the life expectancy, helping to delay or avoid different age-related diseases $[147,148]$. The molecular mechanisms underlying those processes are still not fully elucidated. The role of melatonin as a cardioprotective molecule has been suggested as part of a pathway linked with its antioxidative action in the heart [149]. However, other mechanisms related to ion channel interaction as well as positive effects in mitochondria define its cardioprotective action too. Melatonin acts via its receptors, which are expressed throughout the body, including cardiac tissue [18]. The pleiotropic action of this molecule in cardiac tissue makes melatonin an interesting agent in preventive treatments, particularly in relation to cardiac arrhythmias. Since the work by Tan et al. in 1998 [150], our understanding of melatonin as an antiarrhythmic molecule has increased significantly, becoming an important and promising cardioprotective molecule for the heart. Arrhythmia incidence has been documented to decrease during nighttime hours, when melatonin levels increase 30- to 70-fold. In particular, lifethreatening cardiac arrhythmias (ventricular tachycardia, ventricular fibrillation, and sudden cardiac death) are more likely to occur in the morning after waking up, when melatonin levels are lower or even undetectable.

In summary, melatonin presents different mechanisms of action involving receptor activation, ion channel modulation, improvement of mitochondrial functions, antioxidant effects, and others. Based on these mechanisms and their implications to the aging process, melatonin is considered a key antiaging element through several pathways (Figure 2).

4.2. Melatonin Receptors. Melatonin receptors are characterized to have a wide range of locations. They can be found in different regions within the cell, the plasma membrane being a relevant location linked to the interaction with the melatonin molecule. Melatonin receptors can be found in several systems and organs like the nervous system, kidneys, liver, intestinal tract, prostate gland, uterus, skin, and eyes, as well as the heart and the cardiovascular system [151]. These receptors, named MT1 and MT2, and also known as Mel1a and Mellb, can play their role on melatonin action in the organisms via cell membrane interaction and following a pathway involving $G$ proteins [152]. This melatonin interaction with its receptors at the level of the plasma membrane occurs with high affinity between the molecule of melatonin $(\mathrm{Kd} \sim 0.1 \mathrm{pM})$ and each of MT1 and MT2 [153, 154].

Regarding the structure of the melatonin receptor, both MT1 and MT2 can develop their role as monomers and dimers. The MT1 homodimer forms in a proportion 3- to 4-fold higher than the MT2 homodimer and the MT1/MT2 heterodimer. In addition, there is an MT3 receptor, described as a quinone reductase 2, with an affinity in the nanomolar ranges [155]. Both MT1 and MT2 inhibit adenylate cyclase- 


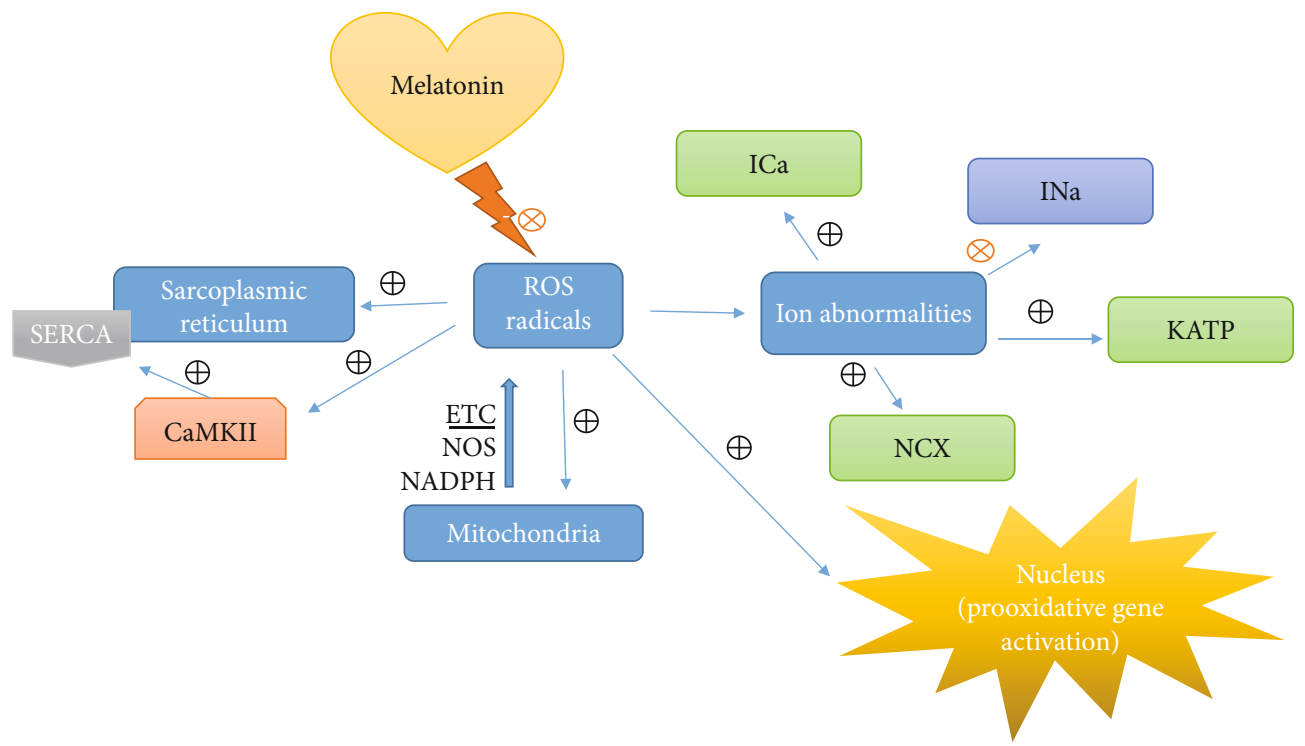

FIGURE 2: Scheme about the effect of reactive oxygen species (ROS) in cardiac tissue at different levels. Also, the potential role of melatonin as

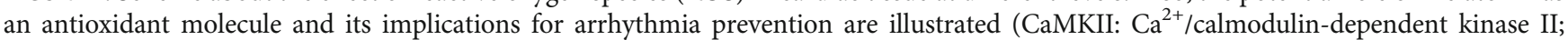
SERCA: sarco/endoplasmic reticulum $\mathrm{Ca}^{2+}$-ATPase; ROS: reactive oxygen species; ICa: calcium current; INa: sodium current; KATP: ATP-sensitive potassium channel; NCX: sodium-calcium exchanger; ETC: electron transport chain; NOS: nitric oxide synthases; NADPH: nicotinamide adenine dinucleotide phosphate hydrogen).

protein kinase A-CREB signaling in target cells by pertussis toxin-sensitive $\mathrm{G} \alpha \mathrm{i}, \beta$, and $\gamma$ and toxin-insensitive $\mathrm{Gq}, \beta$, and $\gamma$ proteins $[151,156]$. The MT1 receptor also increases phosphorylation of mitogen-activated protein kinase $1 / 2$ (MAPK) and extracellular signal-regulated kinase $1 / 2$ (ERK) and increases the potassium conductance through inwardly rectifying (Kir3.x) channels. The effect on potassium channels could be relevant to heart electrophysiology since Kir3.x channels are highly expressed in cardiomyocytes and are usually coupled to acetylcholine and adenosine membrane receptors [157]. In the case of the MT2 melatonin receptor, its activation inhibits both forskolin-stimulated cAMP production and cGMP formation, activates protein kinase $\mathrm{C}(\mathrm{PKC})$ in the nervous system, and decreases calcium-dependent dopamine release in the retina. Native functional MT1/MT2 heterodimers in mouse rod photoreceptors mediate melatonin's enhancement of scotopic light sensitivity through phospholipase $\mathrm{C}$ and $\mathrm{PKC}$ pathways [158]. Different drugs such as Luzindole work as receptor blockers, with an important role in cardiac tissue. Luzindole and 4P-PDOT competitively block MT1 melatonin receptors (in concentrations higher than $300 \mathrm{nM}$ ), and both are inverse agonists in systems with constitutively active MT1 receptors [148-155, 159].

Melatonin can act in the regulation of calcium levels due to its interaction with intracellular proteins such as calmodulin, calreticulin, or tubulin [160], all of these pathways being potentially linked to the action of melatonin in the cardiovascular system directly or indirectly [161]. In particular, the role of the molecule of melatonin in mitochondrial pathways has been described. Melatonin provides a potent protection against mitochondrial-mediated lesions, playing an important role in the organism in terms of energy production [162].
4.3. Antioxidant Effects of Melatonin. Deficiencies in the electron transport chain from mitochondria generates reactive oxygen species and reactive nitrogen species (ROS/RNS) [163-167]. Oxidative stress decreases respiratory complex activity, impairs the electron transport system, and opens the mitochondrial permeability transition pores leading to cell death [165-169]. Melatonin has an antioxidant effect through mitochondria, improving and preserving the good function of complexes I and III and preventing the opening of the mitochondrial permeability transition pores [170173]. In addition, melatonin prevents the high activity of NADPH oxidase, which can be linked to the production of oxidative species beyond mitochondria, considered as the main source of oxidizing species during oxidative phosphorylation $[18,164,174]$.

The reduction of mitochondrial damage in the heart could be related to the negative regulation of angiotensin II type 1 receptor (AT1) by melatonin [13]. In addition, sirtuin-1 and sirtuin-3 are downstream mediators of the cardioprotective actions of melatonin. Sirtuin-3 is a family member that is primarily located in the mitochondria and protects against inflammation and diseases related to oxidative stress. Melatonin elevates sirtuin-3, stimulates superoxide dismutase activity, and suppresses mitochondrial oxidative stress and, via sirtuin-1 and sirtuin-3, it can also prevent isoproterenolinduced mitochondrial injury [175].

Following the previously described pathways, melatonin has been described to have an effect as a powerful antioxidant, with a potency up to 10 times greater than vitamin $\mathrm{E}$ [176], having an important role interacting against oxidative species. Free radicals and nonradical reactive species have been documented as one of the main molecules involved in aging processes, and melatonin could play its role against 
them [163, 177]. Redox biology involves the study of ROS, RNS, and reactive sulfur species as well as their role in the damage of several molecules and tissues. Under physiological conditions, ROS/RNS act as second intracellular messengers modulating signal transduction pathways [164]. A good balance between the production and the removal of free radicals is key to maintaining proper concentrations of this species in the organism, thus avoiding damage. Melatonin may play a crucial role in preserving such a good balance. However, when oxidants increase above healthy levels, oxidative stress occurs and represents a severe risk to the molecular integrity of lipids, proteins, and DNA. Different molecules, including melatonin, could work in the neutralization of reactive species as scavenger molecules, generating a chemical way of counteracting oxidative stress. In particular, the role and interaction with mitochondria could be a good strategic point, as this organelle is considered the main source of oxidation. However, as mentioned before, there are many other pathways to be detected, which create other oxidant species, such as NADPH oxidase, which have their origin in a different system beyond the mitochondrial one.

It is possible to classify different types of antioxidants as (1) nonenzymatic ones (melatonin, vitamins, and GSH) and (2) enzymatic ones (SOD, catalase, thioredoxin, and glutathione peroxidase). It is worthy to mention that the melatonin molecule is 5 times more effective than GSH, for instance [167, 178]. Melatonin stimulates antioxidant enzymes by acting on membrane, cytoplasmic, and nuclear receptors [178, 179]. Low melatonin concentrations increase the expression or activity of SOD, catalase, and glutathione peroxidase $[178,180]$. In addition, melatonin can prevent oxidative stress. The aromatic indole ring of melatonin reduces and repairs electrophilic radicals acting as an electron donor. One molecule of melatonin can neutralize up to 10 toxic reagents, including ROS, RNS, and other free radicals. Moreover, several metabolites formed when melatonin neutralizes harmful reagents are also antioxidants, suggesting that a cascade of reactions increases the efficacy of melatonin. Being a highly lipophilic and hydrophilic compound, melatonin crosses all morphological barriers and acts not only in each cell but also within each subcellular compartment. Additionally, melatonin increases the efficacy of vitamin $\mathrm{E}$, vitamin $\mathrm{C}$, and GSH. Therefore, the elimination of free radicals can be carried out by intracellular interactions independent of any receptor [18].

Since free radicals are continuously produced from oxidative reactions and melatonin production declines through the human lifespan, exogenous melatonin could be used in the aging population to improve health and reduce free radical damage.

4.4. Cardioprotective Effects of Melatonin. The beneficial effect of melatonin on health, disease, and aging has been supported by many in vivo animal studies. In particular, the potential of melatonin intake to improve cardiac function and diminish oxidative stress has been demonstrated [181]. The antiarrhythmic effects of melatonin were first attributed to its notable antioxidant properties. Melatonin has been later suggested as a good candidate for cardiovascular diseases and aging due to its role in modulating electrophysio- logical properties from cell to tissue levels, its relation to oxidative stress, and its important action in repairing and controlling circadian rhythms [182]. Loss of the circadian rhythm regulated by melatonin predisposes the heart to suffer cardiac arrhythmias, particularly ventricular tachycardia, due to conduction disorders and changes in repolarization [15]. Since melatonin levels decline progressively over a lifespan $[171,183]$, loss of melatonin during aging could contribute to a gradually increased predisposition to hypertension and arrhythmias [18].

Melatonin has been shown to have a cardioprotective role, including an antiarrhythmic effect, through different pathways. Melatonin prevents renal damage and arrhythmogenic myocardial remodeling during unilateral ureteral obstruction due to a decrease in oxidative stress, fibrosis, and apoptosis associated with AT1 reduction and Hsp70VDR increase [13]. Other studies have reported a low level in the synthesis of melatonin and low circulating levels of this molecule in patients with coronary heart disease as well as in patients with hypertension and heart failure [184-190]. Cardiac events, such as arrhythmias [191] and others [192], more likely occur during the morning hours when levels of melatonin are considered to be lower [193]. This evidence supports the crucial role of endogenous melatonin in cardiovascular pathologies [194]. Melatonin can have an antiapoptotic effect associated with restoring Nrf2 antioxidant capacity (one of the main molecules responsible for detecting oxidative stress damage), improving this way mitochondria ultrastructure altered by aging [195]. Additionally, cardioprotection by melatonin against oxidative stress and arrhythmias could be widely explained by modulation of ion channels, AP and Cx43 expression [196-198].

The action of melatonin in the opening of Kir3.x channels could explain its control of membrane potential [199]. In the nervous system, there is an effect of melatonin via Kir.3x channels and linked to the circadian rhythm [200]. In fact, it is possible to see an effect on circadian sleep regulation through suppression of GABAergic neurons by melatonin in the lateral hypothalamus (a crucial function for wakefulness) through Kir3.1/Kir3.2 channels and via the MT1 receptor [199]. This interaction via the MT1 receptor inactivates hyperpolarization-activated cyclic nucleotidegated channels [201]. Due to their important role in the nervous system, Kir channels can also be involved in the heart rate decrease mediated by the parasympathetic branch of the autonomic nervous system [202].

Regarding sodium channels $\left(\mathrm{Na}^{+}\right)$, oxidative stress can increase the late sodium current through direct $\mathrm{Na}^{+}$channel modification, prolonging the AP and facilitating the generation of arrhythmogenic triggers known as early afterdepolarizations (EADs) [203-205]. In the case of calcium channels $\left(\mathrm{Ca}^{2+}\right)$, a redox regulation can occur in cardiac myocytes via ryanodine receptors, IP3 receptor and ICa-L $[105,206]$. Different species such as ROS and RNS affect the L-type $\mathrm{Ca}^{2+}$ channel Cav1.2 through cysteine residues that can alter the molecular levels of intracellular $\mathrm{Ca}^{2+}$ or modify specific signaling molecules as in smooth muscle [207]. It has been reported how a low-affinity interaction between melatonin and calmodulin antagonizes the binding of $\mathrm{Ca}^{2+}$, involved 
in its antioxidant action and in electrophysiological signaling [208-211]. In addition, melatonin acutely increases ICa-L in chick cardiac membranes [212] and downregulates voltagesensitive calcium channels in the rat heart [213].

Voltage-gated potassium $(\mathrm{Kv})$ channels contributing to myocardial repolarization are sensitive to oxidative stress $[135,214]$. Particularly, the sulfenic acid, a conserved cysteine residue of Kv1.5 channels, can induce arrhythmia under prolonged oxidative stress $[18,214,215]$. The role of melatonin may depend on time and doses of administration, as it happens via contact with certain channels such as Kv1.3 in lymphocytes or other mechanisms in cardiomyocytes [216]. An example of a dose-dependent action of melatonin is the interaction with KATP channels via mitochondria. The preventive action of melatonin on the permeability transition pore in this channel has been described as an important part of its neuroprotective effect [217]. Its role against mitochondrial dysfunction has been described on myocardial tissue too [170-173]. Nevertheless, the effect in the opening of KATP channels in cardiac tissue at high concentrations of melatonin could be proarrhythmic [218, 219].

On top of the important role of melatonin as a modulator of ion channel properties, it has also a crucial and positive effect in conduction in cardiac tissue due to its interaction with $\mathrm{Cx} 43$, the most abundant connexin in the heart [220]. Connexin proteins assemble into intercellular channels at gap junctions. The largest accumulation of connexins occurs in specialized structures at the ends of cardiomyocytes called intercalated discs. The lateral borders of the myocytes usually show variable amounts of gap junctions depending on age or disease. Melatonin receptor activation has been shown to protect against low potassium-induced ventricular fibrillation by shortening the AP, preserving ventricular electrical activation, and preventing acute changes in $\mathrm{Cx} 43$ distribution [221]. Melatonin has been shown to prevent myocardial abnormalities arising due to structural changes and modification of connexin localization and to improve cardiac conduction [198]. Additionally, melatonin has been shown to protect against arrhythmias by increasing the myocardial Cx43 by PKC in hypertensive rats [198].

Although most studies on melatonin action in the heart focus on its antiarrhythmic protection in relation to its antioxidant properties [222-228], new antiarrhythmic effects have been associated with oxidative stress-independent action on other cardiac properties, such as ventricular activation [197], thus opening the route for the study of additional attributes of this promising therapeutic agent. Some studies have documented an antiarrhythmic effect of melatonin in isolated hearts of female rats when administered continuously from the stage prior to the onset of myocardial ischemia [196]. Also, melatonin reduces arrhythmias when administered during reperfusion. Specifically, melatonin has shown to have a protective action when administered to isolated hearts of hypertensive rats [14]. These animals show greater activity of the enzyme NADPH oxidase, which is one of the main systems for generating free radicals, and, therefore, higher levels of oxidative stress, which is involved in the generation of early and delayed afterdepolarizations [229]. The acute administration of melatonin during low potassium perfusion reduced the incidence of ventricular fibrillation and improved the recovery of sinus rhythm. Protection was mediated by activation of melatonin receptors and by prevention of dephosphorylation and lateralization of $\mathrm{Cx} 43$ [221].

\subsection{Pharmacological Consideration Regarding Melatonin} Administration. Melatonin is a safe molecule without serious adverse effects in a broad range of concentrations either when administered orally or intravenously [230-234]. For antiarrhythmic purposes, two main approaches should be taken into account: first, an acute administration in the context of high proarrhythmic conditions or to treat an ongoing arrhythmia, and second, a chronic preventive one for situations with increased risk of arrhythmias.

The intravenous bioavailability of melatonin is $100 \%$ after a bolus administration and decays biexponentially with half-lives within 2 minutes and 20 minutes [235]. Oral administration reaches a peak concentration around 45 minutes with bioavailability ranging from 3 to $33 \%$, according to different reports. Due to its hydro- and lipophilic properties, melatonin can easily reach the membranes and the inner organelles. Therefore, the potential as an antiarrhythmic to act in the acute scenario is clearly available. However, the evidence is still mainly preclinical $[14,198,221,229,236]$. In the context of ischemia/reperfusion, simultaneous intravenous and intracoronary administration has been proven to be electrophysiologically safe. Formulations of melatonin in polyethylene glycol or saline solution at doses from 14 to $50 \mathrm{mg}$ did not affect the electrophysiological response of the myocardium under ischemia/reperfusion conditions [237, 238]. Unfortunately, both clinical studies failed to prove the cardioprotective effect of melatonin against infarct size. The studies were not designed to evaluate severe reperfusion arrhythmias like sustained ventricular tachycardia and ventricular fibrillation.

Oral doses in an acute cardiac scenario ranged from $3 \mathrm{mg}$ to $25 \mathrm{mg}$ and displayed a safe electrophysiological profile despite mixed cardioprotection results. A conservative approach of $3 \mathrm{mg}$ of melatonin, started on the night following the primary percutaneous coronary intervention and continued daily during the hospitalization, had mixed results on enzymatic myocardial infarct size [239]. Pretreatment with melatonin during five days before coronary artery bypass grafting surgery reduced myocardial injury, heart rate, oxidative stress, and inflammatory markers when compared to placebo [240]. On the other hand, $25 \mathrm{mg}$ melatonin administered for twelve weeks following acute coronary syndrome may aggravate endothelial dysfunction [241]. Interestingly, the combination of $50 \mathrm{mg}$ intravenously and $10 \mathrm{mg}$ orally display cardioprotection in patients undergoing abdominal aortic aneurysm repair, with a risk reduction of $25 \%$ of cardiac morbidity, including postoperative atrial fibrillation [242].

Several safety studies showed the lack of severe side effects of melatonin during chronic and sustained administration [243-245]. Regarding arrhythmias, one report of two patients suffering frequent premature ventricular contractions claimed that arrhythmic events resolved after stopping melatonin $1 \mathrm{mg}$ as their sleeping pills [246]. On the other hand, several studies validated the melatonin safety profile during long periods of 
supervised side effect evaluation. No prospective clinical research has been conducted to evaluate melatonin as an antiarrhythmic. Several preclinical studies postulate melatonin as a preventive agent against ventricular arrhythmias $[13,15$, 197, 198, 247, 248]. The proarrhythmic vs. antiarrhythmic effect of melatonin deserves further translational and clinical studies.

\section{Preventive Perspectives: The Fountain of Youth for the Heart}

We gave an overview of the positive effect of melatonin and focused our attention on its role as a future possible treatment aimed at reducing the risk of cardiac arrhythmias in aged hearts. As described in this review, the structural and functional remodeling that accompanies aging increases susceptibility to atrial and ventricular arrhythmias in humans and in animal models. The increase in oxidative stress with aging plays a major role in this age-associated remodeling. When antioxidant defenses, which decline with aging, are not able to counteract the elevated levels of oxidative stress, arrhythmias can manifest with higher probability. On this basis, we bring here a summary of the variety of positive effects of melatonin. This molecule could be one of the new keys to find the fountain of youth against adverse age-related remodeling of the heart (Figure 3). Several drugs have been described as novel, potential antiarrhythmic agents mainly for the management of AF in the elderly. However, more research is expected to lead to new strategies for prevention or treatment of arrhythmias in the elderly, including ventricular arrhythmias.

Previous studies have described the protective role of melatonin against autophagy and apoptosis in cardiomyocytes via regulation of mitochondrial uncoupling protein 2 (UCP2), producing a mechanism of protection against lipopolysaccharides (LPS) [249]. However, the protective mechanism of melatonin goes far beyond this action, involving different roles in the nervous system [250-252], myocardium remodeling [17] and antioxidant properties [162], all these factors generally involved in its receptor-mediated actions linked to antiarrhythmic properties. This substantiates that melatonin becomes a molecule worthy to be further explored for use in clinical applications. Elevated heterogeneities in cardiac conduction and AP repolarization, which may occur in relation to aging and other cardiac diseases, can be reduced by melatonin via its action in the modulation of myocardial Cx43 [198] and ion channels, improvement of cardiomyocyte physiology, and generation and conduction of APs, ultimately protecting against arrhythmogenesis $[18,56]$.

Moreover, melatonin synchronizes central but also peripheral oscillators like the heart, allowing temporal organization of biological functions through circadian rhythms and improving adaptation of the individual to the internal and external environment, thus working as a good antiaging agent [182]. Furthermore, numerous studies have confirmed the antiarrhythmic protection of melatonin and have related it to its remarkable antioxidant properties under a time- and dose-dependent response. As an example of these facts, studies in hypertensive rat hearts, which have a higher activity of the enzyme NADPH oxidase implicated in oxidative stress

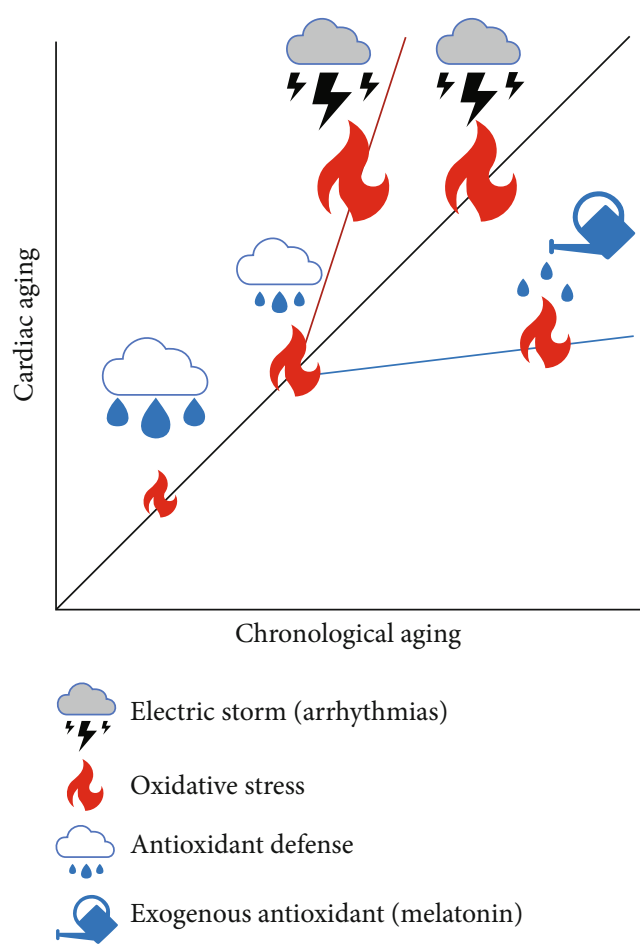

Figure 3: The balance between oxidative stress and antioxidant defenses influence the evolution of cardiac age-induced remodeling and the level of proarrhythmic risk. Increases in oxidative stress anticipate the occurrence of arrhythmic events, whereas antioxidants delay or even abrogate arrhythmias.

and present high arrhythmic risk, have shown that treatment with melatonin has positive effects, avoiding arrhythmias, either sustained ventricular tachycardia or ventricular fibrillation [18, 198, 229].

Based on the number and diversity of major melatonin benefits, there is also a perspective for measuring melatonin not only as a possible treatment to defeat cardiovascular problems but also as a biomarker to detect, control, and follow-up certain disorders. Melatonin could become essential for clinical preventive and therapeutic applications in newborns, children, and adults based on its physiological regulatory effects [182]. However, it is crucial to take into account that its role can be time- and dose-dependent so as to avoid possible adverse effects [246, 253]. In addition, considering that the ability of the pineal gland to produce melatonin is compromised during aging, with a gradual decrease in blood melatonin levels at night, the potential use of melatonin as an early biomarker indicative of adverse age-induced remodeling associated with arrhythmic risk is anticipated [183].

Among the list of potential antiarrhythmic molecules and based on the antioxidant action and pleiotropic effects of melatonin in organisms, it has been described as one of the potential antioxidant targets in cardiac tissue [226]. Melatonin concentrations and its associated effects can highly vary from one individual to another as well as in relation to aging or chronic diseases. Among many effects, melatonin has shown an important role as an inhibitor of lipid peroxidation. Due to this effect, melatonin plays a crucial role in stabilizing cell and organelle membranes, with the final goal 
of protecting them. Besides, melatonin can act as a direct free radical scavenger and also an indirect antioxidant. Additionally, its metabolites are efficient in scavenging ROS and reactive nitrogen species. Melatonin also plays an effective action related to mitochondrial homeostasis [165]. Based on cell energy impairment, apoptosis, and overproduction of ROS as pathogenic mechanisms in aging melatonin could play a crucial role in counteracting deleterious aging [135, 137], effects in the cardiovascular system, particularly considering its antioxidant action. In conclusion, melatonin is a molecule representing a new target to be further tested in clinical trials expanding its application beyond sleep problems or a few already explored disorders. Future studies on dose-response relationships will be crucial to extend the use of melatonin in clinical practice, for both treatment and prevention, particularly in the context of cardiac arrhythmias in aged hearts.

\section{Conflicts of Interest}

The authors declare that they have no conflicts of interest.

\section{Acknowledgments}

This work was supported by the following grants: an ESC research grant funded by the European Society of Cardiology, ERC-StG 638284 funded by the European Research Council, project PID2019-105674RB-I00 funded by Ministerio de Ciencia e Innovación (Spain), and Reference Group T3920R and project LMP124-18 funded by Gobierno de Aragón and FEDER 2014-2020 "Building Europe from Aragón.”

\section{References}

[1] A. Stenling, C. Häggström, M. Norberg, and F. Norström, "Lifetime risk predictions for cardiovascular diseases: competing risks analyses on a population-based cohort in Sweden," Atherosclerosis, vol. 312, pp. 90-98, 2020.

[2] B. J. North and D. A. Sinclair, "The intersection between aging and cardiovascular disease," Circulation Research, vol. 110, no. 8, pp. 1097-1108, 2012.

[3] M. T. Mc Auley, A. M. Guimera, D. Hodgson et al., "Modelling the molecular mechanisms of aging," Bioscience Reports, vol. 37, no. 1, article BSR20160177, 2017.

[4] C. M. Wolf and C. I. Berul, "Molecular mechanisms of inherited arrhythmias," Current Genomics, vol. 9, no. 3, pp. 160168, 2008.

[5] M. Mirza, A. Strunets, W.-K. Shen, and A. Jahangir, "Mechanisms of arrhythmias and conduction disorders in older adults," Clinics in Geriatric Medicine, vol. 28, no. 4, pp. 555-573, 2012.

[6] B. L. Tan, M. E. Norhaizan, W.-P.-P. Liew, and H. Sulaiman Rahman, "Antioxidant and oxidative stress: a mutual interplay in age-related diseases," Frontiers in Pharmacology, vol. 9, p. 1162, 2018.

[7] A. A. Sovari, "Cellular and molecular mechanisms of arrhythmia by oxidative stress," Cardiology Research and Practice, vol. 2016, Article ID 9656078, 7 pages, 2016.

[8] B. Martín-Fernández and R. Gredilla, "Mitochondria and oxidative stress in heart aging," Age, vol. 38, no. 4, pp. 225238, 2016.
[9] Q. Chen, Z. Yi, and J. Cheng, "Atrial fibrillation in aging population,” Aging Medicine, vol. 1, no. 1, pp. 67-74, 2018.

[10] J. A. Vest, X. H. Wehrens, S. R. Reiken et al., "Defective cardiac ryanodine receptor regulation during atrial fibrillation," Circulation, vol. 111, no. 16, pp. 2025-2032, 2005.

[11] A. Capucci, L. Cipolletta, F. Guerra, and I. Giannini, "Emerging pharmacotherapies for the treatment of atrial fibrillation," Expert Opinion on Emerging Drugs, vol. 23, no. 1, pp. 25-36, 2018.

[12] J. B. Schwartz, K. E. Schmader, J. T. Hanlon et al., "Pharmacotherapy in older adults with cardiovascular disease: report from an American College of Cardiology, American Geriatrics Society, and National Institute on Aging Workshop," Journal of the American Geriatrics Society, vol. 67, no. 2, pp. 371-380, 2019.

[13] N. J. Prado, M. Casarotto, J. P. Calvo et al., "Antiarrhythmic effect linked to melatonin cardiorenal protection involves AT1reduction and Hsp70-VDR increase," Journal of Pineal Research, vol. 65, no. 4, article e12513, 2018.

[14] B. Szeiffova Bacova, C. Viczenczova, K. Andelova et al., "Antiarrhythmic effects of melatonin and omega-3 are linked with protection of myocardial $\mathrm{Cx} 43$ topology and suppression of fibrosis in catecholamine stressed normotensive and hypertensive rats," Antioxidants, vol. 9, no. 6, p. 546, 2020.

[15] N. J. Prado, E. M. Muñoz, L. E. Farias Altamirano et al., "Reperfusion arrhythmias increase after superior cervical ganglionectomy due to conduction disorders and changes in repolarization," International Journal of Molecular Sciences, vol. 21, no. 5, p. 1804, 2020.

[16] A. Lochner, E. Marais, and B. Huisamen, "Melatonin and cardioprotection against ischaemia/reperfusion injury: what's new? A review," Journal of Pineal Research, vol. 65, no. 1, article e12490, 2018.

[17] F. Nduhirabandi and G. J. Maarman, "Melatonin in heart failure: a promising therapeutic strategy?," Molecules, vol. 23, no. 7, p. 1819, 2018.

[18] N. J. Prado, M. Segovia-Roldan, E. R. Diez, and E. Pueyo, "Melatonin for a healthy heart rhythm," in Melatonin: The Hormone of Darkness and its Therapeutic Potential and Perspectives, IntechOpen, 2020.

[19] R. Hardeland, "Aging, melatonin, and the pro- and antiinflammatory networks," International Journal of Molecular Sciences, vol. 20, no. 5, p. 1223, 2019.

[20] M. Karasek and R. J. Reiter, "Melatonin and aging," Neuro Endocrinology Letters, vol. 23, Suppl 1, pp. 14-16, 2002.

[21] E. Moore, The Health of Aging Populations, National Academies Press, Washington, D.C., USA, 2001.

[22] C. Franceschi, P. Garagnani, C. Morsiani et al., "The continuum of aging and age-related diseases: common mechanisms but different rates," Frontiers in Medicine, vol. 201, no. 5, p. 61, 2018.

[23] H. T. Blumenthal, "The aging-disease dichotomy: true or false?," The Journals of Gerontology Series A: Biological Sciences and Medical Sciences, vol. 58, no. 2, pp. M138-M145, 2003.

[24] I. M. Rea, D. S. Gibson, V. McGilligan, S. E. McNerlan, H. D. Alexander, and O. A. Ross, "Age and age-related diseases: role of inflammation triggers and cytokines," Frontiers in Immunology, vol. 9, p. 586, 2018. 
[25] V. Gorbunova, A. Seluanov, Z. Mao, and C. Hine, "Changes in DNA repair during aging," Nucleic Acids Research, vol. 35, no. 22, pp. 7466-7474, 2007.

[26] R. Madonna, G. Novo, and C. R. Balistreri, "Cellular and molecular basis of the imbalance between vascular damage and repair in ageing and age-related diseases: as biomarkers and targets for new treatments," Mechanisms of Ageing and Development, vol. 159, pp. 22-30, 2016.

[27] I. Liguori, G. Russo, F. Curcio et al., "Oxidative stress, aging, and diseases," Clinical Interventions in Aging, vol. 13, pp. 757-772, 2018.

[28] E. R. Stadtman, "Protein oxidation in aging and age-related diseases," Annals of the New York Academy of Sciences, vol. 928, no. 1, pp. 22-38, 2001.

[29] A. B. Curtis, R. Karki, A. Hattoum, and U. C. Sharma, "Arrhythmias in patients $\geq 80$ years of age: pathophysiology, management, and outcomes," Journal of the American College of Cardiology, vol. 71, no. 18, pp. 2041-2057, 2018.

[30] J. Chen, M. Hocini, T. B. Larsen, A. Proclemer, E. Sciaraffia, and C. Blomström-Lundqvist, "Clinical management of arrhythmias in elderly patients: results of the European Heart Rhythm Association survey," Europace, vol. 17, no. 2, pp. 314-317, 2015.

[31] A. C. Boyd, N. B. Schiller, D. Leung, D. L. Ross, and L. Thomas, "Atrial dilation and altered function are mediated by age and diastolic function but not before the eighth decade," JACC: Cardiovascular Imaging, vol. 4, no. 3, pp. 234-242, 2011.

[32] J. B. Strait and E. G. Lakatta, "Aging-associated cardiovascular changes and their relationship to heart failure," Heart Failure Clinics, vol. 8, no. 1, pp. 143-164, 2012.

[33] A. Sheydina, D. R. Riordon, and K. R. Boheler, "Molecular mechanisms of cardiomyocyte aging," Clinical Science, vol. 121, no. 8, pp. 315-329, 2011.

[34] R. Vidal, J. U. Wagner, C. Braeuning et al., "Transcriptional heterogeneity of fibroblasts is a hallmark of the aging heart," JCI Insight, vol. 4, no. 22, article e131092, 2019.

[35] L. Lu, J. Guo, Y. Hua et al., "Cardiac fibrosis in the ageing heart: contributors and mechanisms," Clinical and Experimental Pharmacology \& Physiology, vol. 44, Suppl 1, pp. 55-63, 2017.

[36] C. R. Gazoti Debessa, L. B. Mesiano Maifrino, and R. Rodrigues de Souza, "Age related changes of the collagen network of the human heart," Mechanisms of Ageing and Development, vol. 122, no. 10, pp. 1049-1058, 2001.

[37] M. A. Horn and A. W. Trafford, "Aging and the cardiac collagen matrix: novel mediators of fibrotic remodelling," Journal of Molecular and Cellular Cardiology, vol. 93, pp. 175-185, 2016.

[38] J. U. G. Wagner and S. Dimmeler, "Cellular cross-talks in the diseased and aging heart," Journal of Molecular and Cellular Cardiology, vol. 138, pp. 136-146, 2020.

[39] D. M. Kaye and M. D. Esler, "Autonomic control of the aging heart," NeuroMolecular Medicine, vol. 10, no. 3, pp. 179-186, 2008.

[40] M. J. Shen and D. P. Zipes, "Role of the autonomic nervous system in modulating cardiac arrhythmias," Circulation Research, vol. 114, no. 6, pp. 1004-1021, 2014.

[41] S. D. Francis Stuart, L. Wang, W. R. Woodard, G. A. Ng, B. A. Habecker, and C. M. Ripplinger, "Age-related changes in cardiac electrophysiology and calcium handling in response to sympathetic nerve stimulation," The Journal of Physiology, vol. 596, no. 17, pp. 3977-3991, 2018.
[42] O. E. Brodde, U. Konschak, K. Becker et al., "Cardiac muscarinic receptors decrease with age. In vitro and in vivo studies," The Journal of Clinical Investigation, vol. 101, no. 2, pp. 471478, 1998.

[43] N. Ferrara, K. Komici, G. Corbi et al., " $\beta$-Adrenergic receptor responsiveness in aging heart and clinical implications," Frontiers in Physiology, vol. 4, p. 396, 2014.

[44] J. R. Stratton, W. C. Levy, J. H. Caldwell et al., "Effects of aging on cardiovascular responses to parasympathetic withdrawal," Journal of the American College of Cardiology, vol. 41, no. 11, pp. 2077-2083, 2003.

[45] R. P. Xiao, E. D. Tomhave, D. J. Wang et al., “Age-associated reductions in cardiac beta1- and beta2-adrenergic responses without changes in inhibitory $G$ proteins or receptor kinases," The Journal of Clinical Investigation, vol. 101, no. 6, pp. 1273-1282, 1998.

[46] H. Davies, N. Ferrara, and S. E. Harding, "Beta-adrenoceptor function changes with age of subject in myocytes from nonfailing human ventricle," Cardiovascular Research, vol. 31, no. 1, pp. 152-156, 1996.

[47] C. Terrenoire, C. E. Clancy, J. W. Cormier, K. J. Sampson, and R. S. Kass, "Autonomic control of cardiac action potentials: role of potassium channel kinetics in response to sympathetic stimulation," Circulation Research, vol. 96, no. 5, pp. e25-e34, 2005.

[48] H. C. Hartzell, P. F. Méry, R. Fischmeister, and G. Szabo, "Sympathetic regulation of cardiac calcium current is due exclusively to cAMP-dependent phosphorylation," Nature, vol. 351, no. 6327, pp. 573-576, 1991.

[49] B. A. English, M. Appalsamy, A. Diedrich et al., "Tachycardia, reduced vagal capacity, and age-dependent ventricular dysfunction arising from diminished expression of the presynaptic choline transporter," American Journal of Physiology-Heart and Circulatory Physiology, vol. 299, no. 3, pp. H799-H810, 2010.

[50] H. Hotta and S. Uchida, "Aging of the autonomic nervous system and possible improvements in autonomic activity using somatic afferent stimulation," Geriatrics \& Gerontology International, vol. 10, Supplement 1, pp. S127-S136, 2010.

[51] J. L. Freeling and Y. Li, "Age-related attenuation of parasympathetic control of the heart in mice," International Journal of Physiology, Pathophysiology and Pharmacology, vol. 7, no. 3, pp. 126-135, 2015.

[52] A. Sosunov, E. P. Anyukhovsky, and M. R. Rosen, "Adrenergic-cholinergic interaction that modulates repolarization in the atrium is altered with aging," Journal of Cardiovascular Electrophysiology, vol. 13, no. 4, pp. 374-379, 2002.

[53] E. Carmeliet, "Cardiac ionic currents and acute ischemia: from channels to arrhythmias," Physiological Reviews, vol. 79, no. 3, pp. 917-1017, 1999.

[54] A. G. Kléber and Y. Rudy, "Basic mechanisms of cardiac impulse propagation and associated arrhythmias," Physiological Reviews, vol. 84, no. 2, pp. 431-488, 2004.

[55] E. G. Lakatta and D. Levy, "Arterial and cardiac aging: major shareholders in cardiovascular disease enterprises. Part II. The aging heart in health: links to heart disease," Circulation, vol. 107, no. 2, pp. 346-354, 2003.

[56] A. Varró, J. Tomek, N. Nagy et al., "Cardiac transmembrane ion channels and action potentials: cellular physiology and arrhythmogenic behavior," Physiological Reviews, 2020. 
[57] E. Isaac, S. M. Cooper, S. A. Jones, and M. Loubani, "Do ageassociated changes of voltage-gated sodium channel isoforms expressed in the mammalian heart predispose the elderly to atrial fibrillation?," World Journal of Cardiology, vol. 12, no. 4, pp. 123-135, 2020.

[58] W. Dun and P. A. Boyden, "Aged atria: electrical remodeling conducive to atrial fibrillation," Journal of Interventional Cardiac Electrophysiology, vol. 25, no. 1, pp. 9-18, 2009.

[59] M. Dibb, U. Rueckschloss, D. A. Eisner, G. Isenberg, and A. W. Trafford, "Mechanisms underlying enhanced cardiac excitation contraction coupling observed in the senescent sheep myocardium," Journal of Molecular and Cellular Cardiology, vol. 37, no. 6, pp. 1171-1181, 2004.

[60] H. A. Feridooni, K. M. Dibb, and S. E. Howlett, "How cardiomyocyte excitation, calcium release and contraction become altered with age," Journal of Molecular and Cellular Cardiology, vol. 83, pp. 62-72, 2015.

[61] T. A. Bonda, B. Szynaka, M. Sokołowska et al., "Remodeling of the intercalated disc related to aging in the mouse heart," Journal of Cardiology, vol. 68, no. 3, pp. 261-268, 2016.

[62] S. A. Jones, "Ageing to arrhythmias: conundrums of connections in the ageing heart," The Journal of Pharmacy and Pharmacology, vol. 58, no. 12, pp. 1571-1576, 2006.

[63] C. H. Peters, E. J. Sharpe, and C. Proenza, "Cardiac pacemaker activity and aging," Annual Review of Physiology, vol. 82, pp. 21-43, 2020.

[64] J. O. Tellez, M. Mączewski, J. Yanni et al., "Ageing-dependent remodelling of ion channel and $\mathrm{Ca}^{2+}$ clock genes underlying sino-atrial node pacemaking," Experimental Physiology, vol. 96, no. 11, pp. 1163-1178, 2011.

[65] E. D. Larson, J. R. S. Clair, W. A. Sumner, R. A. Bannister, and C. Proenza, "Depressed pacemaker activity of sinoatrial node myocytes contributes to the age-dependent decline in maximum heart rate," Proceedings of the National Academy of Sciences of the United States of America, vol. 110, no. 44, pp. 18011-18016, 2013.

[66] X. Huang, P. Yang, Y. Du, J. Zhang, and A. Ma, “Age-related down-regulation of HCN channels in rat sinoatrial node," Basic Research in Cardiology, vol. 102, no. 5, pp. 429-435, 2007.

[67] S. Signore, A. Sorrentino, G. Borghetti et al., "Late Na+ current and protracted electrical recovery are critical determinants of the aging myopathy," Nature Communications, vol. 6, p. 8803, 2015.

[68] I. R. Josephson, A. Guia, M. D. Stern, and E. G. Lakatta, "Alterations in properties of L-type Ca channels in aging rat heart," Journal of Molecular and Cellular Cardiology, vol. 34, no. 3, pp. 297-308, 2002.

[69] E. J. Benjamin, P. A. Wolf, R. B. D’Agostino, H. Silbershatz, W. B. Kannel, and D. Levy, "Impact of atrial fibrillation on the risk of death: the Framingham Heart Study," Circulation, vol. 98, no. 10, pp. 946-952, 1998.

[70] S. Nattel, A. Maguy, S. Le Bouter, and Y.-H. Yeh, "Arrhythmogenic ion-channel remodeling in the heart: heart failure, myocardial infarction, and atrial fibrillation," Physiological Reviews, vol. 87, no. 2, pp. 425-456, 2007.

[71] C. Pott, L. Eckardt, and J. I. Goldhaber, "Triple threat: the $\mathrm{Na}^{+} / \mathrm{Ca}^{2+}$ exchanger in the pathophysiology of cardiac arrhythmia, ischemia and heart failure," Current Drug Targets, vol. 12, no. 5, pp. 737-747, 2011.

[72] M. U. Koban, A. F. Moorman, J. Holtz, M. H. Yacoub, and K. R. Boheler, "Expressional analysis of the cardiac Na-Ca exchanger in rat development and senescence," Cardiovascular Research, vol. 37, no. 2, pp. 405-423, 1998.

[73] A. M. Lompré, F. Lambert, E. G. Lakatta, and K. Schwartz, "Expression of sarcoplasmic reticulum $\mathrm{Ca}^{2+}$-ATPase and calsequestrin genes in rat heart during ontogenic development and aging," Circulation Research, vol. 69, no. 5, pp. 13801388, 1991.

[74] G. E. Taffet and C. A. Tate, "CaATPase content is lower in cardiac sarcoplasmic reticulum isolated from old rats," The American Journal of Physiology, vol. 264, 5 Part 2, pp. H1609-H1614, 1993.

[75] A. Xu and N. Narayanan, "Effects of aging on sarcoplasmic reticulum $\mathrm{Ca}^{2+}$-cycling proteins and their phosphorylation in rat myocardium," The American Journal of Physiology, vol. 275, no. 6, pp. H2087-H2094, 1998.

[76] Y. Y. Zhou, E. G. Lakatta, and R. P. Xiao, "Age-associated alterations in calcium current and its modulation in cardiac myocytes," Drugs \& Aging, vol. 13, no. 2, pp. 159-171, 1998.

[77] S. Dhein, T. Seidel, A. Salameh et al., "Remodeling of cardiac passive electrical properties and susceptibility to ventricular and atrial arrhythmias," Frontiers in Physiology, vol. 5, p. $424,2014$.

[78] S. A. Jones and M. K. Lancaster, "Progressive age-associated activation of JNK associates with conduction disruption in the aged atrium," Mechanisms of Ageing and Development, vol. 146-148, pp. 72-80, 2015.

[79] J. E. Saffitz, R. B. Schuessler, and K. A. Yamada, "Mechanisms of remodeling of gap junction distributions and the development of anatomic substrates of arrhythmias," Cardiovascular Research, vol. 42, no. 2, pp. 309-317, 1999.

[80] H. M. W. van der Velden and H. J. Jongsma, "Cardiac gap junctions and connexins: their role in atrial fibrillation and potential as therapeutic targets," Cardiovascular Research, vol. 54, no. 2, pp. 270-279, 2002.

[81] B. Burstein and S. Nattel, "Atrial fibrosis: mechanisms and clinical relevance in atrial fibrillation," Journal of the American College of Cardiology, vol. 51, no. 8, pp. 802-809, 2008.

[82] J. A. Jansen, T. A. van Veen, S. de Jong et al., "Reduced Cx43 expression triggers increased fibrosis due to enhanced fibroblast activity," Circulation: Arrhythmia and Electrophysiology, vol. 5, no. 2, pp. 380-390, 2012.

[83] X. Tang, P.-H. Li, and H.-Z. Chen, "Cardiomyocyte senescence and cellular communications within myocardial microenvironments," Frontiers in Endocrinology, vol. 11, p. 280, 2020.

[84] B. Martín-Fernández and R. Gredilla, "Mitochondrial oxidative stress and cardiac ageing," Clínica e Investigación en Arteriosclerosis (English Edition), vol. 30, no. 2, pp. 74-83, 2018.

[85] K. A. Aitbaev, I. T. Murkamilov, and V. V. Fomin, "Molecular mechanisms of aging: the role of oxidative stress and epigenetic modifications," Advances in Gerontology, vol. 32, no. 1-2, pp. 20-28, 2019.

[86] J. N. Peoples, A. Saraf, N. Ghazal, T. T. Pham, and J. Q. Kwong, "Mitochondrial dysfunction and oxidative stress in heart disease," Experimental \& Molecular Medicine, vol. 51, no. 12, 2019.

[87] M. M. Elahi, Y. X. Kong, and B. M. Matata, "Oxidative stress as a mediator of cardiovascular disease," Oxidative Medicine and Cellular Longevity, vol. 2, no. 5, p. 269, 2009. 
[88] C. López-Otín, M. A. Blasco, L. Partridge, M. Serrano, and G. Kroemer, "The hallmarks of aging," Cell, vol. 153, no. 6, pp. 1194-1217, 2013.

[89] P. Kapahi, M. E. Boulton, and T. B. L. Kirkwood, "Positive correlation between mammalian life span and cellular resistance to stress," Free Radical Biology \& Medicine, vol. 26, no. 5, pp. 495-500, 1999.

[90] T. B. L. Kirkwood, "A systematic look at an old problem," Nature, vol. 451, p. 7179, 2008.

[91] T. B. L. Kirkwood, "Understanding the odd science of aging," Cell, vol. 120, no. 4, pp. 437-447, 2005.

[92] V. Obas and R. S. Vasan, "The aging heart," Clinical Science, vol. 132, no. 13, pp. 1367-1382, 2018.

[93] C. Muscari, A. Giaccari, E. Giordano, C. Clô, C. Guarnieri, and C. M. Caldarera, "Role of reactive oxygen species in cardiovascular aging," in Biochemical Mechanisms in Heart Function, E. G. Krause and R. Vetter, Eds., pp. 159-166, Springer US, Boston, MA, 1996.

[94] Y. Quan, Y. Xin, G. Tian, J. Zhou, and X. Liu, "Mitochondrial ROS-modulated mtDNA: a potential target for cardiac aging," Oxidative Medicine and Cellular Longevity, vol. 2020, Article ID 9423593, 11 pages, 2020.

[95] C. T. Madreiter-Sokolowski, C. Thomas, and M. Ristow, "Interrelation between $\mathrm{ROS}$ and $\mathrm{Ca}^{2+}$ in aging and agerelated diseases," Redox Biology, vol. 36, p. 101678, 2020.

[96] R. Zini, A. Berdeaux, and D. Morin, "The differential effects of superoxide anion, hydrogen peroxide and hydroxyl radical on cardiac mitochondrial oxidative phosphorylation," Free Radical Research, vol. 41, no. 10, pp. 1159-1166, 2007.

[97] Y.-K. Lin, Y.-A. Chen, T.-I. Lee, Y.-C. Chen, S.-A. Chen, and Y.-J. Chen, "Aging modulates the substrate and triggers remodeling in atrial fibrillation," Circulation Journal, vol. 82, no. 5, pp. 1237-1244, 2018.

[98] K. J. Schillinger and V. V. Patel, "Atrial fibrillation in the elderly: the potential contribution of reactive oxygen species," Journal of geriatric cardiology: JGC, vol. 9, no. 4, pp. 379-388, 2012.

[99] R. B. Neuman, H. L. Bloom, I. Shukrullah et al., "Oxidative stress markers are associated with persistent atrial fibrillation," Clinical Chemistry, vol. 53, no. 9, pp. 1652-1657, 2007.

[100] N. Morita, A. A. Sovari, Y. Xie et al., "Increased susceptibility of aged hearts to ventricular fibrillation during oxidative stress," American Journal of Physiology. Heart and Circulatory Physiology, vol. 297, no. 5, pp. H1594-H1605, 2009.

[101] B. L. Prosser, R. J. Khairallah, A. P. Ziman, C. W. Ward, and W. J. Lederer, "X-ROS signaling in the heart and skeletal muscle: stretch-dependent local ROS regulates $\left[\mathrm{Ca}^{2+}\right]_{\mathrm{i}}$," Journal of Molecular and Cellular Cardiology, vol. 58, pp. 172$181,2013$.

[102] Q. Li, D. Su, B. O’Rourke, S. M. Pogwizd, and L. Zhou, "Mitochondria-derived ROS bursts disturb $\mathrm{Ca}^{2+}$ cycling and induce abnormal automaticity in guinea pig cardiomyocytes: a theoretical study," American Journal of Physiology. Heart and Circulatory Physiology, vol. 308, no. 6, pp. H623-H636, 2015.

[103] N. T. Aggarwal and J. C. Makielski, "Redox control of cardiac excitability," Antioxidants \& Redox Signaling, vol. 18, no. 4, pp. 432-468, 2013.

[104] L. Liu, J. Li, J. Liu et al., "Involvement of $\mathrm{Na}^{+} / \mathrm{K}^{+}$-ATPase in hydrogen peroxide-induced hypertrophy in cardiac myocytes," Free Radical Biology \& Medicine, vol. 41, no. 10, pp. 1548-1556, 2006.
[105] C. M. Sag, S. Wagner, and L. S. Maier, "Role of oxidants on calcium and sodium movement in healthy and diseased cardiac myocytes," Free Radical Biology \& Medicine, vol. 63, pp. 338-349, 2013.

[106] G. P. Thomas, S. M. Sims, M. A. Cook, and M. Karmazyn, "Hydrogen peroxide-induced stimulation of L-type calcium current in guinea pig ventricular myocytes and its inhibition by adenosine A1 receptor activation," The Journal of Pharmacology and Experimental Therapeutics, vol. 286, no. 3, pp. 1208-1214, 1998.

[107] Y. Yang, W. Shi, N. Cui, Z. Wu, and C. Jiang, "Oxidative stress inhibits vascular KATP channels by S-glutathionylation," The Journal of Biological Chemistry, vol. 285, no. 49, pp. 38641-38648, 2010.

[108] Z. Zhao, Y. Xie, H. Wen et al., "Role of the transient outward potassium current in the genesis of early afterdepolarizations in cardiac cells," Cardiovascular Research, vol. 95, no. 3, pp. 308-316, 2012.

[109] R. Gordan and L.-H. Xie, "Primary effect of reactive oxygen species on electrical remodeling of the heart," Circulation Journal, vol. 78, no. 8, pp. 1834-1836, 2014.

[110] Y. Song, J. C. Shryock, S. Wagner, L. S. Maier, and L. Belardinelli, "Blocking late sodium current reduces hydrogen peroxide-induced arrhythmogenic activity and contractile dysfunction," The Journal of Pharmacology and Experimental Therapeutics, vol. 318, no. 1, pp. 214-222, 2006.

[111] J. C. Makielski, "Late sodium current: a mechanism for angina, heart failure, and arrhythmia," Journal of Cardiovascular Pharmacology, vol. 54, no. 4, pp. 279-286, 2009.

[112] L. C. Hool, "Evidence for the regulation of L-type $\mathrm{Ca}^{2+}$ channels in the heart by reactive oxygen species: mechanism for mediating pathology," Clinical and Experimental Pharmacology \& Physiology, vol. 35, no. 2, pp. 229-234, 2008.

[113] M. Liu, H. Liu, and S. C. Dudley, "Reactive oxygen species originating from mitochondria regulate the cardiac sodium channel," Circulation Research, vol. 107, no. 8, pp. 967-974, 2010.

[114] F. J. Sánchez, V. A. Gonzalez, M. Farrando et al., “Atrial dyssynchrony measured by strain echocardiography as a marker of proarrhythmic remodeling and oxidative stress in cardiac surgery patients," Oxidative Medicine and Cellular Longevity, vol. 2020, Article ID 8895078, 14 pages, 2020.

[115] E. Himelman, M. A. Lillo, J. Nouet et al., "Prevention of connexin-43 remodeling protects against Duchenne muscular dystrophy cardiomyopathy," The Journal of Clinical Investigation, vol. 130, no. 4, pp. 1713-1727, 2020.

[116] A. A. Sovari, S. Iravanian, E. Dolmatova et al., "Inhibition of c-Src tyrosine kinase prevents angiotensin II-mediated connexin-43 remodeling and sudden cardiac death," Journal of the American College of Cardiology, vol. 58, no. 22, pp. 2332-2339, 2011.

[117] J. Kohutova, B. Elsnicova, K. Holzerova et al., "Anti-arrhythmic cardiac phenotype elicited by chronic intermittent hypoxia is associated with alterations in connexin-43 expression, phosphorylation, and distribution," Frontiers in Endocrinology, vol. 9, p. 789, 2019.

[118] Y. Purnomo, Y. Piccart, T. Coenen, J. S. Prihadi, and P. J. Lijnen, "Oxidative stress and transforming growth factor- $\beta 1$ induced cardiac fibrosis," Cardiovascular \& Hematological Disorders Drug Targets, vol. 13, no. 2, pp. 165-172, 2013. 
[119] A. A. Sovari and J. Dudley, "Reactive oxygen species-targeted therapeutic interventions for atrial fibrillation," Frontiers in Physiology, vol. 3, p. 311, 2012.

[120] G. Gao, A. Xie, S. C. Huang et al., "Role of RBM25/LUC7L3 in abnormal cardiac sodium channel splicing regulation in human heart failure," Circulation, vol. 124, no. 10, pp. 1124-1131, 2011.

[121] P. D. Swaminathan, A. Purohit, T. J. Hund, and M. E. Anderson, "CaMKII: linking heart failure and arrhythmias," Circulation Research, vol. 110, no. 12, pp. 1661-1677, 2012.

[122] C. M. Sag, D. P. Wadsack, S. Khabbazzadeh et al., "Calcium/calmodulin-dependent protein kinase II contributes to cardiac arrhythmogenesis in heart failure," Circulation: Heart Failure, vol. 2, no. 6, pp. 664-675, 2009.

[123] Y. Wu, J. Temple, R. Zhang et al., "Calmodulin kinase II and arrhythmias in a mouse model of cardiac hypertrophy," Circulation, vol. 106, no. 10, pp. 1288-1293, 2002.

[124] E. Di Pasquale, F. Lodola, M. Miragoli et al., "CaMKII inhibition rectifies arrhythmic phenotype in a patient-specific model of catecholaminergic polymorphic ventricular tachycardia," Cell Death \& Disease, vol. 4, no. 10, 2013.

[125] A. V. Zima and S. R. Mazurek, "Functional impact of ryanodine receptor oxidation on intracellular calcium regulation in the heart," Reviews of Physiology, Biochemistry and Pharmacology, vol. 171, pp. 39-62, 2016.

[126] M. Mochizuki, M. Yano, T. Oda et al., "Scavenging free radicals by low-dose carvedilol prevents redox-dependent $\mathrm{Ca}^{2+}$ leak via stabilization of ryanodine receptor in heart failure," Journal of the American College of Cardiology, vol. 49, no. 16, pp. 1722-1732, 2007.

[127] A. V. Zima and L. A. Blatter, "Redox regulation of cardiac calcium channels and transporters," Cardiovascular Research, vol. 71, no. 2, pp. 310-321, 2006.

[128] T. L. Domeier, L. A. Blatter, and A. V. Zima, "Alteration of sarcoplasmic reticulum $\mathrm{Ca}^{2+}$ release termination by ryanodine receptor sensitization and in heart failure," The Journal of Physiology, vol. 587, Part 21, pp. 5197-5209, 2009.

[129] D. Terentyev, I. Györke, A. E. Belevych et al., "Redox modification of ryanodine receptors contributes to sarcoplasmic reticulum $\mathrm{Ca}^{2+}$ leak in chronic heart failure," Circulation Research, vol. 103, no. 12, pp. 1466-1472, 2008.

[130] A. F. Dulhunty, N. A. Beard, and A. D. Hanna, "Regulation and dysregulation of cardiac ryanodine receptor (RyR2) open probability during diastole in health and disease," The Journal of General Physiology, vol. 140, no. 2, pp. 87-92, 2012.

[131] A. E. Belevych, D. Terentyev, S. Viatchenko-Karpinski et al., "Redox modification of ryanodine receptors underlies calcium alternans in a canine model of sudden cardiac death," Cardiovascular Research, vol. 84, no. 3, pp. 387-395, 2009.

[132] A. E. Belevych, D. Terentyev, R. Terentyeva et al., "The relationship between arrhythmogenesis and impaired contractility in heart failure: role of altered ryanodine receptor function," Cardiovascular Research, vol. 90, no. 3, pp. 493502, 2011.

[133] J. R. Burgoyne, H. Mongue-Din, P. Eaton, and A. M. Shah, "Redox signaling in cardiac physiology and pathology," Circulation Research, vol. 111, no. 8, pp. 1091-1106, 2012.

[134] A. A. Sovari and S. Dudley, "Antioxidant therapy for atrial fibrillation: lost in translation?," Heart, vol. 98, no. 22, pp. 1615-1616, 2012.
[135] E. M. Jeong, M. Liu, M. Sturdy et al., "Metabolic stress, reactive oxygen species, and arrhythmia," Journal of Molecular and Cellular Cardiology, vol. 52, no. 2, pp. 454-463, 2012.

[136] A. A. Sovari, "Antioxidant Therapy for Atrial Fibrillation: What Is the Next Step?," Cardiology Research and Practice, vol. 2011, Article ID 429537, 2 pages, 2011.

[137] K. Yang and S. C. Dudley, "Oxidative stress and atrial fibrillation," Circulation, vol. 128, no. 16, pp. 1724-1726, 2013.

[138] V. N. Gladyshev, "The free radical theory of aging is dead. Long live the damage theory!," Antioxidants \& Redox Signaling, vol. 20, no. 4, pp. 727-731, 2014.

[139] E. Cecon, C. Legros, J. A. Boutin, and R. Jockers, "Journal of Pineal Research guideline for authors: Defining and characterizing melatonin targets," Journal of Pineal Research, no. article e12712, 2020.

[140] L. H. Opie and S. Lecour, "Melatonin has multiorgan effects," European Heart Journal-Cardiovascular Pharmacotherapy, vol. 2, no. 4, pp. 258-265, 2016.

[141] A. B. Lerner, J. D. Case, Y. Takahashi, T. H. Lee, and W. Mori, "Isolation of melatonin, the pineal gland factor that lightens melanocytes," Journal of the American Chemical Society, vol. 80, no. 10, p. 2587, 1958.

[142] X. D. Martin, H. Z. Malina, M. C. Brennan, P. H. Hendrickson, and P. R. Lichter, "The ciliary body-the third organ found to synthesize indoleamines in humans," European Journal of Ophthalmology, vol. 2, no. 2, pp. 67-72, 1992.

[143] S. R. Pandi-Perumal, V. Srinivasan, G. J. M. Maestroni, D. P. Cardinali, B. Poeggeler, and R. Hardeland, "Melatonin: nature's most versatile biological signal?," The FEBS Journal, vol. 273, no. 13, pp. 2813-2838, 2006.

[144] N. Zisapel, "New perspectives on the role of melatonin in human sleep, circadian rhythms and their regulation," British Journal of Pharmacology, vol. 175, no. 16, pp. 3190-3199, 2018.

[145] R. J. Reiter, D.-X. Tan, and L. Fuentes-Broto, "Melatonin: a multitasking molecule," Progress in Brain Research, vol. 181, pp. 127-151, 2010.

[146] Y.-J. Song, C.-B. Zhong, and W. Wu, "Cardioprotective effects of melatonin: focusing on its roles against diabetic cardiomyopathy," Biomedicine \& Pharmacotherapy, vol. 128, p. 110260, 2020.

[147] Y. Touitou and E. Haus, "Alterations with aging of the endocrine and neuroendocrine circadian system in humans," Chronobiology International, vol. 17, no. 3, pp. 369-390, 2000.

[148] S. R. Pandi-Perumal, N. Zisapel, V. Srinivasan, and D. P. Cardinali, "Melatonin and sleep in aging population," Experimental Gerontology, vol. 40, no. 12, pp. 911-925, 2005.

[149] S. Zare, F. S. Heydari, A. W. Hayes, R. J. Reiter, M. R. Zirak, and G. Karimi, "Melatonin attenuates chemical-induced cardiotoxicity," Human \& Experimental Toxicology, no. article 960327120959417, 2020.

[150] D. X. Tan, L. C. Manchester, R. J. Reiter, W. Qi, S. J. Kim, and G. H. El-Sokkary, "Ischemia/reperfusion-induced arrhythmias in the isolated rat heart: prevention by melatonin," Journal of Pineal Research, vol. 25, no. 3, pp. 184-191, 1998.

[151] R. M. Slominski, R. J. Reiter, N. Schlabritz-Loutsevitch, R. S. Ostrom, and A. T. Slominski, "Melatonin membrane receptors in peripheral tissues: distribution and functions," Molecular and Cellular Endocrinology, vol. 351, no. 2, pp. 152-166, 2012. 
[152] B. Stauch, L. C. Johansson, and V. Cherezov, "Structural insights into melatonin receptors," The FEBS Journal, vol. 287, no. 8, pp. 1496-1510, 2020.

[153] B. Stauch, L. C. Johansson, M. C. JD et al., "Structural basis of ligand recognition at the human MT1 melatonin receptor," Nature, vol. 569, no. 7755, pp. 284-288, 2019.

[154] L. C. Johansson, B. Stauch, M. C. JD et al., "XFEL structures of the human MT2 melatonin receptor reveal the basis of subtype selectivity," Nature, vol. 569, no. 7755, pp. 289-292, 2019.

[155] J. A. Boutin and G. Ferry, "Is there sufficient evidence that the melatonin binding site MT3 is quinone reductase 2?," The Journal of Pharmacology and Experimental Therapeutics, vol. 368, no. 1, pp. 59-65, 2019.

[156] E. Cecon, A. Oishi, and R. Jockers, "Melatonin receptors: molecular pharmacology and signalling in the context of system bias," British Journal of Pharmacology, vol. 175, no. 16, pp. 3263-3280, 2018.

[157] H. Hibino, A. Inanobe, K. Furutani, S. Murakami, I. Findlay, and Y. Kurachi, "Inwardly rectifying potassium channels: their structure, function, and physiological roles," Physiological Reviews, vol. 90, no. 1, pp. 291-366, 2010.

[158] K. Baba, A. Benleulmi-Chaachoua, A. S. Journé et al., "Heteromeric MT1/MT2 melatonin receptors modulate photoreceptor function," Science Signaling, vol. 6, no. 296, article ra89, 2013.

[159] R. Jockers, P. Delagrange, M. L. Dubocovich et al., "Update on melatonin receptors: IUPHAR Review 20," British Journal of Pharmacology, vol. 173, no. 18, pp. 2702-2725, 2016.

[160] S. R. Pandi-Perumal, I. Trakht, V. Srinivasan et al., "Physiological effects of melatonin: role of melatonin receptors and signal transduction pathways," Progress in Neurobiology, vol. 85, no. 3, pp. 335-353, 2008.

[161] D. Choi, "Potency of melatonin in living beings," Development \& reproduction, vol. 17, no. 3, pp. 149-177, 2013.

[162] A. Hacışevki and B. Baba, "An overview of melatonin as an antioxidant molecule: a biochemical approach," in Melatonin molecular biology, clinical and pharmaceutical approaches, 2018.

[163] H. J. Forman, "Redox signaling: an evolution from free radicals to aging," Free Radical Biology \& Medicine, vol. 97, pp. 398-407, 2016.

[164] W. Dröge, "Free radicals in the physiological control of cell function," Physiological Reviews, vol. 82, no. 1, pp. 47-95, 2002.

[165] S. A. Ganie, T. A. Dar, A. H. Bhat et al., "Melatonin: a potential anti-oxidant therapeutic agent for mitochondrial dysfunctions and related disorders," Rejuvenation Research, vol. 19, no. 1, pp. 21-40, 2016.

[166] S. Bolisetty and E. A. Jaimes, "Mitochondria and reactive oxygen species: physiology and pathophysiology," International Journal of Molecular Sciences, vol. 14, no. 3, pp. 6306-6344, 2013.

[167] I. Afanas'ev, "ROS and RNS signaling in heart disorders: could antioxidant treatment be successful?," Oxidative Medicine and Cellular Longevity, vol. 2011, Article ID 293769, 13 pages, 2011.

[168] G. Morciano, C. Giorgi, M. Bonora et al., "Molecular identity of the mitochondrial permeability transition pore and its role in ischemia-reperfusion injury," Journal of Molecular and Cellular Cardiology, vol. 78, pp. 142-153, 2015.
[169] A. J. Donato, R. G. Morgan, A. E. Walker, and L. A. Lesniewski, "Cellular and molecular biology of aging endothelial cells," Journal of Molecular and Cellular Cardiology, vol. 89, Part B, pp. 122-135, 2015.

[170] G. Petrosillo, G. Colantuono, N. Moro et al., "Melatonin protects against heart ischemia-reperfusion injury by inhibiting mitochondrial permeability transition pore opening," American Journal of Physiology-Heart and Circulatory Physiology, vol. 297, no. 4, pp. H1487-H1493, 2009.

[171] G. Paradies, V. Paradies, F. M. Ruggiero, and G. Petrosillo, "Mitochondrial bioenergetics decay in aging: beneficial effect of melatonin," Cellular and Molecular Life Sciences, vol. 74, no. 21, pp. 3897-3911, 2017.

[172] G. Petrosillo, N. D. Venosa, M. Pistolese et al., "Protective effect of melatonin against mitochondrial dysfunction associated with cardiac ischemiareperfusion: role of cardiolipin," The FASEB Journal, vol. 20, no. 2, pp. 269-276, 2006.

[173] G. Petrosillo, N. Moro, V. Paradies, F. M. Ruggiero, and G. Paradies, "Increased susceptibility to $\mathrm{Ca} 2+$-induced permeability transition and to cytochrome $\mathrm{c}$ release in rat heart mitochondria with aging: effect of melatonin," Journal of Pineal Research, vol. 48, no. 4, pp. 340-346, 2010.

[174] R. Radi, "Oxygen radicals, nitric oxide, and peroxynitrite: redox pathways in molecular medicine," Proceedings of the National Academy of Sciences of the United States of America, vol. 115, no. 23, pp. 5839-5848, 2018.

[175] S. Naaz, S. Mishra, P. K. Pal, A. Chattopadhyay, A. R. Das, and D. Bandyopadhyay, "Activation of SIRT1/PGC $1 \alpha /$ SIRT3 pathway by melatonin provides protection against mitochondrial dysfunction in isoproterenol induced myocardial injury," Heliyon, vol. 6, no. 10, article e05159, 2020.

[176] R. J. Reiter and D.-X. Tan, "Melatonin: a novel protective agent against oxidative injury of the ischemic/reperfused heart," Cardiovascular Research, vol. 58, no. 1, pp. 10-19, 2003.

[177] R. J. Reiter, J. C. Mayo, D.-X. Tan, R. M. Sainz, M. AlatorreJimenez, and L. Qin, "Melatonin as an antioxidant: under promises but over delivers," Journal of Pineal Research, vol. 61, no. 3, pp. 253-278, 2016.

[178] C. Rodriguez, J. C. Mayo, R. M. Sainz et al., "Regulation of antioxidant enzymes: a significant role for melatonin," Journal of Pineal Research, vol. 36, no. 1, pp. 1-9, 2004.

[179] K. Ding, H. Wang, J. Xu et al., "Melatonin stimulates antioxidant enzymes and reduces oxidative stress in experimental traumatic brain injury: the Nrf2-ARE signaling pathway as a potential mechanism," Free Radical Biology and Medicine, vol. 73, pp. 1-11, 2014.

[180] K. Yanar, B. Simsek, and U. Çakatay, "Integration of melatonin related redox homeostasis, aging, and circadian rhythm," Rejuvenation Research, vol. 22, no. 5, pp. 409-419, 2019.

[181] H.-M. Zhang and Y. Zhang, "Melatonin: a well-documented antioxidant with conditional pro-oxidant actions," Journal of Pineal Research, vol. 57, no. 2, pp. 131-146, 2014.

[182] S. Tordjman, S. Chokron, R. Delorme et al., "Melatonin: pharmacology, functions and therapeutic benefits," Current Neuropharmacology, vol. 15, no. 3, pp. 434-443, 2017.

[183] B. Poeggeler, R. J. Reiter, D. X. Tan, L. D. Chen, and L. C. Manchester, "Melatonin, hydroxyl radical-mediated oxidative damage, and aging: a hypothesis," Journal of Pineal Research, vol. 14, no. 4, pp. 151-168, 1993. 
[184] P. Brugger, W. Marktl, and M. Herold, "Impaired nocturnal secretion of melatonin in coronary heart disease," The Lancet, vol. 345, no. 8962, article 1408, 1995.

[185] A. Domínguez-Rodríguez, P. Abreu-González, M. J. García, J. Sanchez, F. Marrero, and D. de Armas-Trujillo, "Decreased nocturnal melatonin levels during acute myocardial infarction," Journal of Pineal Research, vol. 33, no. 4, pp. 248252, 2002.

[186] M. Koziróg, A. R. Poliwczak, P. Duchnowicz, M. KoterMichalak, J. Sikora, and M. Broncel, "Melatonin treatment improves blood pressure, lipid profile, and parameters of oxidative stress in patients with metabolic syndrome," Journal of Pineal Research, vol. 50, no. 3, pp. 261-266, 2011.

[187] A. Dominguez-Rodriguez, P. Abreu-Gonzalez, and R. J. Reiter, "The potential usefulness of serum melatonin level to predict heart failure in patients with hypertensive cardiomyopathy," International Journal of Cardiology, vol. 174, no. 2, pp. 415-417, 2014.

[188] L. Girotti, M. Lago, O. Ianovsky et al., "Low urinary 6sulfatoxymelatonin levels in patients with severe congestive heart failure," Endocrine, vol. 22, no. 3, pp. 245-248, 2003.

[189] G. Dzida, A. Prystupa, P. Lachowska-Kotowska et al., "Alteration in diurnal and nocturnal melatonin serum level in patients with chronic heart failure," Annals of Agricultural and Environmental Medicine, vol. 20, no. 4, pp. 745-748, 2013.

[190] A. Dominguez-Rodriguez, P. Abreu-Gonzalez, R. Piccolo, G. Galasso, and R. J. Reiter, "Melatonin is associated with reverse remodeling after cardiac resynchronization therapy in patients with heart failure and ventricular dyssynchrony," International Journal of Cardiology, vol. 221, pp. 359-363, 2016.

[191] D. Siegel, D. M. Black, D. G. Seeley, and S. B. Hulley, "Circadian variation in ventricular arrhythmias in hypertensive men," The American Journal of Cardiology, vol. 69, no. 4, pp. 344-347, 1992.

[192] Z. Jiki, S. Lecour, and F. Nduhirabandi, "Cardiovascular benefits of dietary melatonin: a myth or a reality?," Frontiers in Physiology, vol. 9, p. 528, 2018.

[193] A. Altun, M. Yaprak, M. Aktoz, A. Vardar, U. A. Betul, and G. Ozbay, "Impaired nocturnal synthesis of melatonin in patients with cardiac syndrome X," Neuroscience Letters, vol. 327, no. 2, pp. 143-145, 2002.

[194] C. J. McMullan, E. B. Rimm, E. S. Schernhammer, and J. P. Forman, "A nested case-control study of the association between melatonin secretion and incident myocardial infarction," Heart, vol. 103, no. 9, pp. 694-701, 2017.

[195] M. Fernández-Ortiz, R. K. Sayed, J. Fernández-Martínez et al., "Melatonin/Nrf2/NLRP3 connection in mouse heart mitochondria during aging," Antioxidants, vol. 9, no. 12, 2020.

[196] E. R. Diez, L. V. Prados, A. Carrion, Z. A. Z. Ponce, and R. M. Miatello, "A novel electrophysiologic effect of melatonin on ischemia/reperfusion-induced arrhythmias in isolated rat hearts," Journal of Pineal Research, vol. 46, no. 2, pp. 155160, 2009.

[197] K. A. Sedova, O. G. Bernikova, J. I. Cuprova et al., “Association between antiarrhythmic, electrophysiological, and antioxidative effects of melatonin in ischemia/reperfusion," International Journal of Molecular Sciences, vol. 20, no. 24, p. $6331,2019$.
[198] T. Benova, C. Viczenczova, J. Radosinska et al., "Melatonin attenuates hypertension-related proarrhythmic myocardial maladaptation of connexin-43 and propensity of the heart to lethal arrhythmias," Canadian Journal of Physiology and Pharmacology, vol. 91, no. 8, pp. 633-639, 2013.

[199] C. S. Nelson, J. L. Marino, and C. N. Allen, "Melatonin receptors activate heteromeric G-protein coupled Kir3 channels," Neuroreport, vol. 7, no. 3, pp. 717-720, 1996.

[200] L. M. Hablitz, H. E. Molzof, K. E. Abrahamsson, J. M. Cooper, R. A. Prosser, and K. L. Gamble, "GIRK channels mediate the nonphotic effects of exogenous melatonin," The Journal of Neuroscience, vol. 35, no. 45, pp. 14957-14965, 2015.

[201] Y. Huang, Y. Li, and Z. Leng, "Melatonin inhibits GABAergic neurons in the hypothalamus consistent with a reduction in wakefulness," Neuroreport, vol. 31, no. 2, pp. 92-98, 2020.

[202] K. Wickman and D. E. Clapham, "Ion channel regulation by G proteins," Physiological Reviews, vol. 75, no. 4, pp. 865-885, 1995.

[203] P. E. Light, C. H. R. Wallace, and J. R. B. Dyck, "Constitutively active adenosine monophosphate-activated protein kinase regulates voltage-gated sodium channels in ventricular myocytes," Circulation, vol. 107, no. 15, pp. 1962-1965, 2003.

[204] J. Ma, A. Luo, and P. Zhang, "Effect of hydrogen peroxide on persistent sodium current in guinea pig ventricular myocytes," Acta Pharmacologica Sinica, vol. 26, no. 7, pp. 828834, 2005.

[205] C. A. Ward and W. R. Giles, "Ionic mechanism of the effects of hydrogen peroxide in rat ventricular myocytes," The Journal of Physiology, vol. 500, Part 3, pp. 631-642, 1997.

[206] I. Bogeski and B. A. Niemeyer, "Redox regulation of ion channels," Antioxidants \& Redox Signaling, vol. 21, no. 6, pp. 859-862, 2014.

[207] M. Trebak, R. Ginnan, H. A. Singer, and D. Jourd'heuil, "Interplay between calcium and reactive oxygen/nitrogen species: an essential paradigm for vascular smooth muscle signaling," Antioxidants \& Redox Signaling, vol. 12, no. 5, pp. 657-674, 2010.

[208] H. E. D. J. Ter Keurs and P. A. Boyden, "Calcium and arrhythmogenesis,” Physiological Reviews, vol. 87, no. 2, pp. 457-506, 2007.

[209] H. M. Yeung, M. W. Hung, and M. L. Fung, "Melatonin ameliorates calcium homeostasis in myocardial and ischemiareperfusion injury in chronically hypoxic rats," Journal of Pineal Research, vol. 45, no. 4, pp. 373-382, 2008.

[210] C. A. Valverde, D. Kornyeyev, M. Ferreiro, A. D. Petrosky, A. Mattiazzi, and A. L. Escobar, "Transient $\mathrm{Ca}^{2+}$ depletion of the sarcoplasmic reticulum at the onset of reperfusion," Cardiovascular Research, vol. 85, no. 4, pp. 671-680, 2010.

[211] L. A. Gonano, M. Sepúlveda, Y. Rico et al., "Calcium-calmodulin kinase II mediates digitalis-induced arrhythmias," Circulation. Arrhythmia and Electrophysiology, vol. 4, no. 6, pp. 947-957, 2011.

[212] Y. A. Mei, P. P. Lee, H. Wei, Z. H. Zhang, and S. F. Pang, "Melatonin and its analogs potentiate the nifedipinesensitive high-voltage-activated calcium current in the chick embryonic heart cells," Journal of Pineal Research, vol. 30, no. 1, pp. 13-21, 2001.

[213] L. D. Chen, P. Kumar, R. J. Reiter et al., "Melatonin reduces $3 \mathrm{H}$-nitrendipine binding in the heart," Proceedings of the Society for Experimental Biology and Medicine, vol. 207, no. 1, pp. 34-37, 1994. 
[214] L. K. Svoboda, K. G. Reddie, L. Zhang et al., "Redox-sensitive sulfenic acid modification regulates surface expression of the cardiovascular voltage-gated potassium channel Kv1.5," Circulation Research, vol. 111, no. 7, pp. 842-853, 2012.

[215] R. Bhuyan and S. Chakraborti, "Oxidative Stress and Modulation of Cardiac Kv1.5 Channel," in Oxidative Stress in Heart Diseases, S. Chakraborti, N. Dhalla, N. Ganguly, and M. Dikshit, Eds., Springer, Singapore, 2019.

[216] Z. Varga, G. Panyi, M. Péter Jr. et al., "Multiple binding sites for melatonin on Kv1.3.," Biophysical Journal, vol. 80, no. 3, pp. 1280-1297, 2001.

[217] M. Waseem, H. Tabassum, and S. Parvez, "Melatonin modulates permeability transition pore and 5-hydroxydecanoate induced KATP channel inhibition in isolated brain mitochondria," Mitochondrion, vol. 31, pp. 1-8, 2016.

[218] H. Nakaya, "Role of ATP-sensitive $\mathrm{K}^{+}$channels in cardiac arrhythmias," Journal of Cardiovascular Pharmacology and Therapeutics, vol. 19, no. 3, pp. 237-243, 2014.

[219] D. A. Brown, M. A. Aon, C. R. Frasier et al., "Cardiac arrhythmias induced by glutathione oxidation can be inhibited by preventing mitochondrial depolarization," Journal of Molecular and Cellular Cardiology, vol. 48, no. 4, pp. 673-679, 2010.

[220] K. Andelova, T. Egan Benova, B. Szeiffova Bacova et al., "Cardiac connexin-43 hemichannels and pannexin1 channels: provocative antiarrhythmic targets," International Journal of Molecular Sciences, vol. 22, no. 1, p. 260, 2021.

[221] N. J. Prado, T. Egan Beňová, E. R. Diez et al., "Melatonin receptor activation protects against low potassium-induced ventricular fibrillation by preserving action potentials and connexin-43 topology in isolated rat hearts," Journal of Pineal Research, vol. 67, no. 4, article e12605, 2019.

[222] P. Dobsak, J. Siegelová, J. C. Eicher et al., "Melatonin protects against ischemia-reperfusion injury and inhibits apoptosis in isolated working rat heart," Pathophysiology, vol. 9, no. 3, pp. 179-187, 2003.

[223] R. Vazan and T. Ravingerova, "Protective effect of melatonin against myocardial injury induced by epinephrine," Journal of Physiology and Biochemistry, vol. 71, no. 1, pp. 43-49, 2015.

[224] S. Bertuglia and R. J. Reiter, "Melatonin reduces ventricular arrhythmias and preserves capillary perfusion during ischemia-reperfusion events in cardiomyopathic hamsters," Journal of Pineal Research, vol. 42, no. 1, pp. 55-63, 2007.

[225] Y.-M. Lee, H.-R. Chen, G. Hsiao, J.-R. Sheu, J.-J. Wang, and M.-H. Yen, "Protective effects of melatonin on myocardial ischemia/reperfusion injury in vivo," Journal of Pineal Research, vol. 33, no. 2, pp. 72-80, 2002.

[226] S. Kaneko, K. Okumura, Y. Numaguchi et al., "Melatonin scavenges hydroxyl radical and protects isolated rat hearts from ischemic reperfusion injury," Life Sciences, vol. 67, no. 2, pp. 101-112, 2000.

[227] O. Szárszoi, G. Asemu, J. Vanecek, B. Ost'ádal, and F. Kolár, "Effects of melatonin on ischemia and reperfusion injury of the rat heart," Cardiovascular Drugs and Therapy, vol. 15, no. 3, pp. 251-257, 2001.

[228] C. Lagneux, M. Joyeux, P. Demenge, C. Ribuot, and D. Godin-Ribuot, "Protective effects of melatonin against ischemia-reperfusion injury in the isolated rat heart," Life Sciences, vol. 66, no. 6, pp. 503-509, 2000.

[229] E. R. Diez, N. F. Renna, N. J. Prado et al., "Melatonin, given at the time of reperfusion, prevents ventricular arrhythmias in isolated hearts from fructose-fed rats and spontaneously hypertensive rats," Journal of Pineal Research, vol. 55, no. 2, pp. 166-173, 2013.

[230] A. Dominguez-Rodriguez, P. Abreu-Gonzalez, and R. J. Reiter, "Clinical aspects of melatonin in the acute coronary syndrome," Current Vascular Pharmacology, vol. 7, no. 3, pp. 367-373, 2009.

[231] N. G. Harpsøe, L. P. H. Andersen, I. Gögenur, and J. Rosenberg, "Clinical pharmacokinetics of melatonin: a systematic review," European Journal of Clinical Pharmacology, vol. 71, no. 8, pp. 901-909, 2015.

[232] H. F. Galley, D. A. Lowes, L. Allen, G. Cameron, L. S. Aucott, and N. R. Webster, "Melatonin as a potential therapy for sepsis: a phase I dose escalation study and an ex vivo whole blood model under conditions of sepsis," Journal of Pineal Research, vol. 56, no. 4, pp. 427-438, 2014.

[233] L. P. Andersen, M. U. Werner, M. M. Rosenkilde et al., "Pharmacokinetics of oral and intravenous melatonin in healthy volunteers," BMC Pharmacology and Toxicology, vol. 17, p. 8, 2016.

[234] L. P. Andersen, M. U. Werner, M. M. Rosenkilde et al., "Pharmacokinetics of high-dose intravenous melatonin in humans," Journal of Clinical Pharmacology, vol. 56, no. 3, pp. 324-329, 2016.

[235] B. Claustrat, J. Brun, and G. Chazot, "The basic physiology and pathophysiology of melatonin," Sleep Medicine Reviews, vol. 9, no. 1, pp. 11-24, 2005.

[236] T. Benova, V. Knezl, C. Viczenczova, B. S. Bacova, J. Radosinska, and N. Tribulova, "Acute anti-fibrillating and defibrillating potential of atorvastatin, melatonin, eicosapentaenoic acid and docosahexaenoic acid demonstrated in isolated heart model," Journal of Physiology and Pharmacology, vol. 66, no. 1, pp. 83-89, 2015.

[237] S. Ekeloef, N. Halladin, S. Fonnes et al., "Effect of intracoronary and intravenous melatonin on myocardial salvage index in patients with ST-elevation myocardial infarction: a randomized placebo controlled trial," Journal of Cardiovascular Translational Research, vol. 10, no. 5, pp. 470-479, 2017.

[238] A. Dominguez-Rodriguez, P. Abreu-Gonzalez, J. M. de la Torre-Hernandez et al., "Effect of intravenous and intracoronary melatonin as an adjunct to primary percutaneous coronary intervention for acute ST-elevation myocardial infarction: results of the Melatonin Adjunct in the acute myocaRdial Infarction treated with Angioplasty trial," Journal of Pineal Research, vol. 62, no. 1, article e12374, 2017.

[239] P. Ghaeli, S. Vejdani, A. Ariamanesh, and A. Hajhossein Talasaz, "Effect of melatonin on cardiac injury after primary percutaneous coronary intervention: a randomized controlled trial," Iranian journal of pharmaceutical research: IJPR, vol. 14, no. 3, pp. 851-855, 2015.

[240] K. H. Dwaich, F. G. Y. Al-Amran, B. I. M. Al-Sheibani, and H. A. Al-Aubaidy, "Melatonin effects on myocardial ischemia-reperfusion injury: impact on the outcome in patients undergoing coronary artery bypass grafting surgery," International Journal of Cardiology, vol. 221, pp. 977-986, 2016.

[241] J. A. Zahid, A. Isbrand, J. Kleif et al., "The effect of melatonin on endothelial dysfunction in patients after acute coronary syndrome: the MEFACS randomized clinical trial," Journal of Pineal Research, vol. 67, no. 3, article e12600, 2019.

[242] I. Gögenur, B. Kücükakin, L. Panduro Jensen, R. J. Reiter, and J. Rosenberg, "Melatonin reduces cardiac morbidity and 
markers of myocardial ischemia after elective abdominal aortic aneurism repair: a randomized, placebo-controlled, clinical trial," Journal of Pineal Research, vol. 57, no. 1, pp. 1015, 2014.

[243] B. Kücükakin, J. Lykkesfeldt, H. J. Nielsen, R. J. Reiter, J. Rosenberg, and I. Gögenur, "Utility of melatonin to treat surgical stress after major vascular surgery-a safety study," Journal of Pineal Research, vol. 44, no. 4, pp. 426-431, 2008.

[244] M. L. Seabra, M. Bignotto, L. R. Pinto, and S. Tufik, "Randomized, double-blind clinical trial, controlled with placebo, of the toxicology of chronic melatonin treatment," Journal of Pineal Research, vol. 29, no. 4, pp. 193-200, 2000.

[245] A. Nickkholgh, H. Schneider, M. Sobirey et al., "The use of high-dose melatonin in liver resection is safe: first clinical experience," Journal of Pineal Research, vol. 50, no. 4, pp. 381-388, 2011.

[246] L. J. de Vries, T. Géczy, and T. Szili-Torok, "Sleep medications containing melatonin can potentially induce ventricular arrhythmias in structurally normal hearts: a 2-patient report," Journal of Cardiovascular Pharmacology, vol. 70, no. 4, pp. 267-270, 2017.

[247] E. Sahna, E. Olmez, and A. Acet, "Effects of physiological and pharmacological concentrations of melatonin on ischemiareperfusion arrhythmias in rats: can the incidence of sudden cardiac death be reduced?," Journal of Pineal Research, vol. 32, no. 3, pp. 194-198, 2002.

[248] T. E. Benova, C. Viczenczova, B. S. Bacova et al., "Obesityassociated alterations in cardiac connexin- 43 and PKC signaling are attenuated by melatonin and omega- 3 fatty acids in female rats," Molecular and Cellular Biochemistry, vol. 454, no. 1-2, pp. 191-202, 2019.

[249] P. Pan, H. Zhang, L. Su, X. Wang, and D. Liu, "Melatonin balance the autophagy and apoptosis by regulating UCP2 in the LPS-induced cardiomyopathy," Molecules, vol. 23, no. 3, p. $675,2018$.

[250] G. Escames, M. Macias, J. Leon et al., "Calcium-dependent effects of melatonin inhibition of glutamatergic response in rat striatum," Journal of Neuroendocrinology, vol. 13, no. 5, pp. 459-466, 2001.

[251] T.-Y. Choi, J. E. Kwon, E. S. Durrance, S.-H. Jo, S.-Y. Choi, and K.-T. Kim, "Melatonin inhibits voltage-sensitive $\mathrm{Ca}^{2+}$ channel-mediated neurotransmitter release," Brain Research, vol. 1557, pp. 34-42, 2014.

[252] A. Ayar, D. J. Martin, M. Ozcan, and H. Kelestimur, "Melatonin inhibits high voltage activated calcium currents in cultured rat dorsal root ganglion neurones," Neuroscience Letters, vol. 313, no. 1-2, pp. 73-77, 2001.

[253] Y. Wu, F. Si, L. Luo, and Q. Yi, "Serum levels of melatonin may contribute to the pathogenesis of heart failure in children with median age of 1 year," The Journal of Pediatrics, vol. 94, no. 4, pp. 446-452, 2018. 